\title{
Optimum Design of Polymer Electrolyte Membrane Fuel Cell with Graded Porosity Gas Diffusion Layer
}

\author{
Y. Zhang1, A. Verma² and R. Pitchumani ${ }^{2}$ \\ Advanced Materials and Technologies Laboratory \\ Department of Mechanical Engineering \\ Virginia Tech \\ Blacksburg, Virginia 24060
}

\begin{abstract}
Variation in the local current density along a polymer electrolyte membrane (PEM) fuel cell often causes sharp temperature and stress gradients that affect the membrane durability and service life of fuel cells. Towards minimizing the variation in local current density, and potentially improving fuel cell reliability, this paper explores the use of functionally graded porosity in the gas diffusion electrode layers along the flow direction. A computational model for fuel cell is used together with a numerical optimization method to determine the optimum porosity distribution along the length of the channel, with the objective of maximizing power density while limiting the current density variation. The optimum porosity distribution and the corresponding local current density distribution are compared and discussed in detail for different operating conditions. Experimental studies are conducted to measure the local current density distribution in a fuel cell with a segmented current collector and to evaluate the effects
\end{abstract}

${ }^{1}$ Now with General Motors Company, Pontiac, MI

2 Corresponding Author: pitchu@vt.edu, +1 540-231-1776 
of graded porosity distribution in the gas diffusion layer. It is shown that using an optimally graded porosity distribution improves the uniformity in current density along the length of the channel by up to a factor of 10 , while maximizing the power density.

KEY WORDS: Proton exchange membrane (PEM) fuel cell, Graded porosity electrode, Current density distribution, Optimization, Membrane durability, Fuel cell reliability

\section{Introduction}

Proton exchange membrane (PEM) fuel cells are considered a viable alternative energy source for mobile and stationary applications owing to high power density, simple design and pollution free operation. However, widespread commercialization of PEM fuel cells is primarily challenged by their low reliability in service, caused by membrane electrode assembly (MEA) degradation and failure. During the operation of a PEM fuel cell, significant variation in local current density could exist along the length of the channel due to the reduced reactant concentrations leading to sharp temperature and stress gradients. The temperature and stress gradients affect the water management and may lead to localized hot spots and pin-holes, causing membrane degradation and failure in some cases [1-6]. Since MEA degradation dramatically affects the performance and the life of fuel cells, it is important to mitigate the variation of the local current density to ensure the operation reliability of fuel cells.

Several studies have been reported in the literature to determine the current density distribution in fuel cells using in situ experimental techniques and numerical simulations. Stumper et al. [7] discussed three different techniques for investigating current density distribution and their relative benefits. For the partial membrane electrode assembly (MEA) approach either segments of MEA were masked or several MEAs with partially catalyzed active area were tested to determine localized current density. In the second method, several 
electrically isolated subcells were placed at various locations along the flow channel and were controlled by a separate load. In the third method, a passive graphite resistor network was placed between the flow field plate and the current collector plate to test potential drop across the resistors to obtain the local current density distribution. Mench et al. [8] built segmented flow plates for both anode and cathode sides, which were fabricated by embedding gold plated stainless steel ribs in a polycarbonate block, acting as segmented current collectors. A similar approach was used in [9], where a measuring gasket was specifically designed and inserted between the flow field plate and the gas diffusion layer to measure the local current by the current collecting strips in the gasket. Natarajan et al. [10] investigated the local current density distributions using segmented current collectors and gas diffusion layers. The printed circuit board technology, adopted from [11,12], was used to create a segmented current collector and flow field. The segmented current collector approach was also used in air-breathing PEM fuels cell to study the transient and steady state current density distributions in [13] and [14].

Another method to test the local current density distribution is to measure the electromagnetic field throughout the cell $[15,16]$. Freunberger et al. [17] used a number of very thin wires placed in parallel with the channels and solved a Laplace equation to convert this measurement into the current density in sections parallel to the flow channels. Wang and Liu [18] measured the current density under the channel and shoulder, separately, by loading only the specific areas with catalyst. Gerteisen et al. [19] studied the effects of operating conditions on current density distribution and high frequency resistance in a segmented PEM fuel cell. Luo and Liu [20] used partially catalyzed membrane electrode assemblies to investigate the difference in current density at inlet channel, land and the outlet channel. Besides experimental work, numerical simulation studies are also reported [1,21-24] on investigating the local current 
density distribution under different design factors including material properties, geometry parameters and operating conditions.

The previous studies show that the local current density is not uniform inside the cell and decrease due to the consumption of the reactant gases along the length of the channel. The current density distribution can be manipulated by modifying component material properties such as the porosity of gas diffusion layers (GDLs). The purpose of the gas diffusion layers, made of porous media, in a fuel cell is to effectively distribute the reactant gases into the catalyst layers for electrochemical reactions, and to allow for electronic conduction simultaneously. During the operation of the cell, reactant species concentrations decrease along the channel owing to reactant consumption, which leads to a non-uniform species distribution and, in turn, non-uniform current density distribution. Guran et al. [25] developed a onedimensional half-cell model to investigate the influence of the effective porosity of GDL on the cell performance, considering that the pores maybe partially filled with liquid water and thus changing the local porosity. A similar model was employed in [26], and the non-uniform porosity along the thickness of the cell was investigated by four different continuous functions of position to study its effect on the cell performance including the oxygen mass fraction distribution, current density distribution and membrane phase potential distribution. Yan et al. [27] studied the effect of flow distributor and diffusion layer geometries and morphologies on the species transport phenomena suggesting that increase in porosity and water content leads to better performance. The influence of uniform and gradient porosity across the thickness of the GDL on liquid water transport was analyzed in [28]. Min et al. [29] performed a parameter sensitivity analysis in the numerical modeling of PEM fuel cell, including the effect of different porosity values on the cell performance. Tang et al. [30] investigated the effects of porositygraded micorporous layers (MPL), by printing MPLs with different content of $\mathrm{NH}_{4} \mathrm{Cl}$ pore- 
former and the porosity of the graded MPL decreased from the inner layer to outer. It was found that the fuel cells with graded MPL had better performance owing to better water and gas transportation. Schweiss et al. [31] doped MPLs of GDLs with multi walled carbon nanotubes, leading to improved conductivity and increase in larger mean pore diameter, and thus an improvement in mass transport. It is envisioned that increasing the porosity will result in more reactant gases being transported to catalyst sites for electrochemical reactions. Therefore, tailoring the gas diffusion layer to have a gradually increasing porosity along the channel will provide for a more uniform distribution of the reactant gases into the catalyst layer, thus achieving a more uniform current density distribution along the length of the channel and forms the scope of current study.

This paper proposes an approach to reduce the local current density variation by using functionally graded porosity in the gas diffusion layer along the gas channel, with the goal of determining the optimum porosity distribution of the gas diffusion layer so as to achieve a desired uniformity in current density while maximizing the power density. By tailoring the porosity variation in the GDLs such that the porosity increases gradually along the flow length, the availability of the reactants at the catalyst sites can be controlled so as to yield uniformity of the electrochemical reaction and, in turn, the local current density. To this end, a twodimensional numerical model is developed to describe the transport and electrochemical phenomena inside a conventional PEM fuel cell. The porosity distribution is parameterized using a power law functional form or piecewise continuous variation, such that the porosity increases monotonically along the length of the channel. Systematic parametric studies are conducted to obtain the optimum porosity and current density distributions for different operating conditions. The optimum results from the simulations, in turn, is used to fabricate GDLs with the graded porosity distribution which are tested in a fuel cell test station to 
investigate the improvement in the local current density distribution. The computational and experimental studies are used to demonstrate effectiveness of the method of using variable porosity GDLs for minimizing local current density variation in fuel cells.

The presentation is organized as follows: the mathematical model for a conventional PEM fuel cell is presented in the next section, Section 2, followed by the optimal design of the graded porosity variations in Section 3. The experimental studies are described in Section 4, and the results of the computational and experimental studies are presented and discussed in Section 5.

\section{Mathematical Model}

Figure 1 shows an illustration of a typical PEM fuel cell comprised of: (1) an anode current collector plate, with integrated fuel flow channels; (2) an anode gas diffusion layer (GDL); (3) an anode catalyst layer, where hydrogen oxidation reaction (HOR) takes place; (4) a proton exchange membrane; (5) a cathode catalyst layer for the oxygen reduction reaction (ORR); (6) a cathode gas diffusion layer; and (7) a cathode current collector providing for oxygen gas transport. Hydrogen is fed into the channel and transported through the anode gas diffusion layer and arrives at the anode catalyst sites, where it dissociates into protons and electrons. Protons are transported with water inside the cell through the membrane to the cathode catalyst layer, while electrons are transported from the anode to cathode side through an external circuit. Oxygen $\left(\mathrm{O}_{2}\right)$ transported though the cathode gas diffusion layer to the cathode catalyst sites reacts with protons and electrons under the effect of catalyst and generates water.

The gas transport inside the cell is governed by the coupled continuity, momentum, and species conservation equations. The water transport from anode to cathode is modeled as source terms representing the osmotic drag, and is included in the momentum equations for the catalyst layers and the membrane. The electron transport is governed by solid phase potential 
equation in the catalyst and gas diffusion at the anode and cathode sides, while the proton transport is expressed as membrane phase potential equation in the two catalyst layers and the membrane. The electrochemical reactions contribute as the source terms based on the ButlerVolmer expressions for both the phase potentials. The coupled governing equations presented here is formulated for the entire domain comprising the seven regions described above for a two-dimensional cross section, with the thickness of the cell represented by $x$-direction and the length of the gas channel by $y$-direction. A single phase model is chosen for simplicity with major emphasis on reaction consumption. The concept of graded GDLs can be further explored using a two phase model to account for pore blocking. The unified formulations for the twodimensional isothermal numerical model $[1,2,5]$ is summarized as follows with specific source terms (Table 1) and associated boundary conditions as depicted in Fig. 2:

$$
\begin{gathered}
\nabla \cdot(\rho \vec{V})=S_{C} \\
\nabla \cdot(\rho \vec{V} \vec{V})=-\nabla p+\nabla \cdot \tau+S_{V} \\
\nabla \cdot\left(\rho \vec{V} y_{i}\right)=\nabla \cdot\left(\rho D_{i}^{e f f} \nabla y_{i}\right)+S_{i} \\
\nabla \cdot\left(\sigma_{j}^{e f f} \nabla \phi_{j}\right)+S_{j}=0 ; \quad j=s, m
\end{gathered}
$$

where $\rho$ is the fluid mixture density; $\vec{V}$ is the superficial velocity vector or average volume velocity vector; $p$ is the pressure; $\boldsymbol{\tau}$ is the stress tensor; $y_{i}$ represents the $i$-th species mass fraction; $D_{i}^{e f f}$ is the effective diffusivity of individual species; $\phi_{j}, j=\mathrm{m}$ and $\mathrm{s}$, denotes the solid phase potential and membrane phase potential respectively and $\sigma_{j}^{e f f}, j=\mathrm{m}$ and $\mathrm{s}$ are the effective electrical conductivity for solid phase and ionic conductivity of the membrane, respectively.

The source term $S_{C}$ represents mass source or sink term in two catalyst layers; $S_{V}$ represents pressure gradient due to flow through porous media, and includes both pressure gradient due 
to flow through porous media and electroosmotic force in the MEA since protons are driven by osmotic force and transported from the anode catalyst layer to the cathode catalyst layer with water; $S_{i}$ represents the consumption of $\mathrm{H}_{2}$ in the anode catalyst layer, and consumption of $\mathrm{O}_{2}$ and the generation of $\mathrm{H}_{2} \mathrm{O}$ in the cathode catalyst layer; $S_{j}$ represents current generation owing to the electrochemical reactions in the two catalyst layers, expressed by transfer current densities. All the source terms shown in the equations [1-5] are listed in Table 1.

The local current density vector can be written as: $\vec{\imath}_{\text {local }}=i_{x} \hat{\mathbf{1}}+i_{y} \hat{\mathbf{\jmath}}$, where $i_{x}$ denotes the component in the x-direction and $i_{y}$ denotes the component in the y-direction. Each of these components is, in turn, can be expressed as the sum of the current due to the proton transport $\left(i_{m, x}, i_{m, y}\right)$ and that due to electron transport $\left(i_{s, x}, i_{s, y}\right)$. The electronic current is obtained as the product of the effective electronic conductivity and the electronic potential gradient. Likewise, the protonic current is given by the product of the effective protonic conductivity and the protonic potential gradient. The components of the current density are, therefore, expressed as follows:

$$
\begin{aligned}
& i_{x}=i_{s, x}+i_{m, x}=-\sigma_{s}^{e f f} \frac{\partial \phi_{s}}{\partial x}-\sigma_{m}^{e f f} \frac{\partial \phi_{m}}{\partial x} \\
& i_{y}=i_{s, y}+i_{m, y}=-\sigma_{s}^{e f f} \frac{\partial \phi_{s}}{\partial y}-\sigma_{m}^{e f f} \frac{\partial \phi_{m}}{\partial y}
\end{aligned}
$$

Thus, the local current density, I, is defined as the magnitude of the local current density vector, expressed as follows:

$$
I=\left|\vec{l}_{\text {local }}\right|=\sqrt{i_{x}^{2}+i_{y}^{2}}
$$

The average current density of the fuel cell, $I_{\text {ave }}$ is calculated by integrating the local current density over the area, which is also equivalent to the integration of the transfer current densities over the entire volume of the catalyst layer, and then divided by the cross active area, $A$, as: 


$$
I_{\text {ave }}=\frac{1}{A} \int \vec{l}_{\text {local }} \cdot d A=\frac{1}{A} \int j_{a} \cdot d V=\frac{1}{A} \int j_{c} \cdot d V
$$

Since the purpose of the gas diffusion layers in a fuel cell is to distribute the reactant gases into the catalyst layers for electrochemical reactions and to transport electrons simultaneously, the transport phenomena inside the gas diffusion layer is significantly affected by the porosity distribution. The effective diffusivity of individual species, $D_{i}^{e f f}$, in the gas diffusion layer follows the expression of Bruggeman correlation based on the effects of porosity and tortuosity in the porous media [32]:

$$
D_{i}^{\text {eff }}=\varepsilon_{e f f}^{1.5} D_{i, r e f}\left(\frac{T}{353}\right)^{1.5}\left(\frac{1}{p}\right)
$$

in which, $D_{i, r e f}$ is the diffusivity of the species $\mathrm{i}$ at the reference temperature and pressure: $T_{r e f}=$ $353 \mathrm{~K}$ and $p_{\text {ref }}=1 \mathrm{~atm}$, listed in Table 2 . The effective electrical conductivity of solid phase, $\sigma_{s}^{\text {eff }}$, is expressed as the function of the porosity, $\varepsilon$, and the electrical conductivity of the solid material $\sigma_{s}$ :

$$
\sigma_{s}^{e f f}=(1-\varepsilon) \cdot \sigma_{s}
$$

For a uniform porous medium used as the gas diffusion layer, the permeability is expressed as a function of porosity based on the Carman-Kozeny relationship:

$$
k=c_{Z} \frac{\varepsilon^{3}}{(1-\varepsilon)^{2}}
$$

where $c_{Z}=1.0 \times 10^{-10}$, which corresponds to $k=1.76 \times 10^{-11} \mathrm{~m}^{2}$ for $\varepsilon=0.4$.

It is known that concentration of oxygen varies significantly in cathode channel in comparison to that of hydrogen in the anode channel. Therefore, it may be reasoned that the use of variable porosity design for the gas diffusion layer is expected to be more effective on the cathode side, than the anode side. Accordingly, the porosity of the GDL at the anode side is fixed at 0.4 , and only the GDL on the cathode side is considered with graded porosity distribution. 


\section{Optimal Design of Gas Diffusion Layer}

The goal of the study is to determine the optimum variation of the cathode GDL porosity so as to maintain a desired uniformity of the local current density along the fuel cell. To this end, the GDL porosity, $\varepsilon$, variation is parameterized in a functional form of the location $y$ along the length of the fuel cell, such that the optimization problem is one of determining the parameters of the functional variations. Two parameterized functions are considered in the study:

(1) The cathode GDL porosity, $\varepsilon$, is parameterized as three piecewise constant (positive) values, $\varepsilon_{1}, \varepsilon_{2}$ and $\varepsilon_{3}$, each spanning a third of the length of the fuel cell, $L$, such that:

$$
\varepsilon=\left\{\begin{array}{l}
\varepsilon_{1}\left(0<y \leq \frac{L}{3}\right) \\
\varepsilon_{2}\left(\frac{L}{3}<y \leq \frac{2 L}{3}\right) \\
\varepsilon_{3}\left(\frac{2 L}{3}<y \leq L\right)
\end{array}\right.
$$

(2) The cathode GDL porosity, $\varepsilon$, is parameterized as a continuation variation along the length of the fuel cell, as a power law function,

$$
\varepsilon=\varepsilon_{0}+a(y / L)^{b}
$$

where $\varepsilon_{0}, a$ and $b$ are positive coefficients, implying that the porosity increases along the channel.

The objective of the study is to determine the optimum cathode GDL porosity variations, in terms of the values of $\varepsilon_{1}, \varepsilon_{2}$ and $\varepsilon_{3}$ for a piecewise constant cathode catalyst distribution and $\varepsilon_{0}$, $c$ and $d$ for the power law distribution, to maximize the power density $\left(P_{d}\right)$ of the cell, while limiting the variation of the local current density to a certain value. Mathematically, the optimization problem is written as:

Piecewise Constant Variation of $\varepsilon$ 


$$
\begin{gathered}
\text { Maximize } P_{d} \\
\varepsilon_{1}, \varepsilon_{2}, \varepsilon_{3}
\end{gathered}
$$

subject to:

$$
\left.\begin{array}{c}
\frac{\Delta I}{I_{\min }}<\delta \\
0<\varepsilon_{1}<1 \\
0<\varepsilon_{2}<1 \\
0<\varepsilon_{3}<1 \\
\varepsilon_{\text {ave }}=\left(\frac{\varepsilon_{1}+\varepsilon_{2}+\varepsilon_{3}}{3}\right)<0.88
\end{array}\right\}
$$

\section{Power Law Variation of $\varepsilon$}

$$
\begin{gathered}
\text { Maximize } P_{d} \\
\varepsilon_{0}, a, b
\end{gathered}
$$

subject to:

$$
\left.\begin{array}{c}
\frac{\Delta I}{I_{\min }}<\delta \\
0<\varepsilon_{0}<1 \\
0<a<1-\varepsilon_{0} \\
b>0 \\
\varepsilon_{\text {ave }}<0.88
\end{array}\right\}
$$

where $\delta$ is the desired level of uniformity of the current density distribution, $I_{\max }$ and $I_{\min }$ are, respectively, the maximum and the minimum values of the local current density variation along the length of the fuel cell, and $\Delta I$ is the magnitude of the local current density variation, $I_{\max }-I_{\min }$. Note that the constraint on $c$ in Eq. (17) is to reflect the physical consistency of maintaining the local porosity less than unity. Furthermore, the average porosity, $\varepsilon_{a v e}$, is constrained to be less than 0.88 owing to the limitations posed by the strength and resistance to current transport in GDL.

The optimization problems presented by Eqs. (14)-(15) and Eqs. (16)-(17) were each solved using the Nelder-Mead Simplex method [21] combined with a numerical simulation model of PEM fuel cell to satisfy both the objective function and the constraints. The fuel cell model developed in Section 2 was implemented in the commercial software, Ansys Fluent, by using 
user-defined functions to describe the source terms and the coefficients. The governing equations were solved numerically to determine the power density, $P_{d}$, and the local current density variation, $\Delta I / I_{\text {min }}$, which, in turn, were used to solve the optimization problem. Figure 3 shows the flow chart of the optimization process: the initial guesses of parameters $\varepsilon_{1}, \varepsilon_{2}$ and $\varepsilon_{3}$ or $\varepsilon_{0}, a$ and $b$ are supplied to the numerical fuel cell model. The normalized current density variation, $\Delta I / I_{\min }$, and the power density, $P_{d}$, are calculated based on the numerical simulation with parameters $\varepsilon_{1}, \varepsilon_{2}$ and $\varepsilon_{3}$ or $\varepsilon_{0}, a$ and $b$ and returned to the optimizer for mathematical checks of optimality of solution and constraint satisfaction. The values of $\varepsilon_{1}, \varepsilon_{2}$ and $\varepsilon_{3}$ or $\varepsilon_{0}, a$ and $b$ are iteratively updated followed by simulation of fuel cell performance until the optimum values of $\varepsilon_{1}, \varepsilon_{2}$ and $\varepsilon_{3}$ or $\varepsilon_{0}, a$ and $b$ are determined. The mathematical details of the NelderMead Simplex search are omitted here for brevity but may be found in Refs. [21-23].

\section{Experimental Studies}

Experimental studies were conducted on measuring the local current density in fuel cells with graded porosity distribution, with the objective of validating the numerical model as well as corroborating the optimization results. A segmented current collector [7-9] was used to measure the local current density along the flow length of a single channel fuel cell, as depicted in Fig. 4(a). Figure 4(b) shows an exploded view of the fuel cell constructed of the following components, as labeled in the figure: (1) Anode plate with a single straight hydrogen channel in the middle, in which the electrically non-conductive plate was made by curing Epoxy 815 resin with glass fiber reinforcement to increase the strength; (2) Anode non-segmented current collector made of a commercial Nickel mesh product from Dexmet (Wallingford, CT); (3) Anode and cathode gas diffusion layers with membrane electrode assembly between them. SIGRACET $^{\circledR}$ GDL 10BB carbon papers (SGL Technologies, Germany) were used for anode and 
cathode GDLs and the MEA was made from cast film based on Nafion (NRE-211, DuPont, Wilmington, DE) with catalyst loading of $0.3 \mathrm{mg} / \mathrm{cm}^{2}$, an active area of $9.8 \mathrm{~cm}^{2}$ (width $1.4 \mathrm{~cm}$ and length $7.0 \mathrm{~cm}$ ); (4) Cathode current collector made of nickel mesh from Dexmet, segmented into six parts with equal areas to measure the local current density; (5) Cathode plate with single straight oxygen channel aligned with the anode channel and copper wires in contact with the segmented cathode current collector for an external circuit; and (6) Teflon gaskets for sealing the anode and cathode gas diffusion layers and the current collectors. The cell was tightened at the torque of $10 \mathrm{lbf}-\mathrm{in} . /$ bolt to ensure an even pressure distribution on the cell to avoid cell damage at higher pressures.

Figure 4(c) shows the fuel cell unit (item 10) connected to the measurement system, comprising a 850e Scribner fuel cell test station (Scribner Associates, Southern Pines, NC), item 7 in Fig. 4(c), integrated with 890C electrical load station (item 8 in Fig. 4(c)) and connected to a personal computer. The six copper wires from the fuel cell (item 10 in Fig. 4(c)) were connected to a $30 \mathrm{~m} \Omega$ resistor, individually. An Agilent 34970A data acquisition system (Keysight Technologies, CA), item 9 in Fig. 4c, was connected to the six resistors to measure the voltage drop through each of them, from which the local current and current density were calculated.

In the study, discrete GDL with three piecewise constant porosities were designed to be used along the channel length. The variable porosity GDL was constructed using three Nickel mesh screens, each of length $L / \beta$ and identical thickness, with different open areas in the screen combined with a carbon paper backing, as illustrated in Fig. 5.

The measurements of local current density variation along the length of the fuel cell with the variable porosity cathode GDL are discussed in the next section, along with in comparison with the results of the numerical simulation and optimization. 


\section{Results and Discussion}

Figure 6 presents the optimum porosity distribution and the corresponding current density distribution along the channel in the membrane compared with those associated with constant porosities for: $\mathrm{E}_{\text {cell }}=0.35 \mathrm{~V}$ [Figs. $6(\mathrm{a})$ and (b)] and $=0.50 \mathrm{~V}$ [Figs. 6(c) and (d)]. The operating conditions used in the simulations are: cell temperature, $T=353 \mathrm{~K}$, cell pressure, $p_{a}=p_{c}=3$ atm, anode mass flow rate, $m_{a}=6.5 \times 10^{-5} \mathrm{~kg} / \mathrm{s}$, and cathode mass flow rate, $m_{c}=4.0 \times 10^{-4} \mathrm{~kg} / \mathrm{s}$, which is defined as the base operating conditions. Figure 6(a) shows the optimum porosity distribution (solid line) for cell voltage, $E_{\text {cell }}=0.35 \mathrm{~V}$ for $\Delta I / I_{\min }=10 \%$, and the corresponding uniform porosity (dash line), $\varepsilon=0.307$, which equals the average value of the optimum porosity distribution along the channel. The optimum porosity distribution follows a power law expression with $\varepsilon_{0}=0.16, a=0.58$ and $b=3.02$. It can be seen that the porosity increases slowly along the channel at the near inlet region, followed by a steep increase at the outlet reaching a value of 0.66 . This behavior can be attributed to the fact that the oxygen concentration decreases along the channel resulting in steep increase in porosity to allow more oxygen to diffuse into the catalyst sites at the outlet region.

The corresponding current density distribution is illustrated in Fig. 6(b). The average current density for the optimum porosity is $11,567 \mathrm{~A} / \mathrm{m}^{2}$ with the maximum of $12,107 \mathrm{~A} / \mathrm{m}^{2}$ and a minimum of $11,015 \mathrm{~A} / \mathrm{m}^{2}$ and $\Delta I / I_{\min }=10 \%$, whereas for uniform porosity distribution, $\varepsilon$ $=0.307$, the average current density is $11,500 \mathrm{~A} / \mathrm{m}^{2}$ with the maximum of $14,434 \mathrm{~A} / \mathrm{m}^{2}$ and the minimum of $7,133 \mathrm{~A} / \mathrm{m}^{2}$, resulting into a variation of $\Delta I / I_{\min }=102 \%$. It is observed that with the graded porosity distribution, the local current density variation is greatly reduced while maintaining the same average current density. A similar trend is observed for $E_{\text {cell }}=0.50 \mathrm{~V}$ in Figs. $6(\mathrm{c})$ and (d): for the constant porosity of 0.482 , the current distribution has a variation of $\Delta I / I_{\min }=12 \%$ with an average current density of $9,931 \mathrm{~A} / \mathrm{m}^{2}$, represented as the dash line in 
Fig. 6(d), whereas with an optimum porosity gradation, the variation of the local current density is reduced to $5 \%$ with the average current density of $9,890 \mathrm{~A} / \mathrm{m}^{2}$. It can be noted that with the graded porosity distribution, the local current density variation is significantly reduced while maintaining a similar average current density compared to that for uniform porosity.

The optimum porosity and current density distributions, for $\Delta I / I_{\min }=10 \%$, for $E_{\text {cell }}=0.20$ $\mathrm{V}, 0.35 \mathrm{~V}$ and $0.50 \mathrm{~V}$, at the base operating conditions are presented in Fig. 7. It is observed that the optimum porosity distribution and the corresponding local current density distribution for $E_{\text {cell }}=0.20 \mathrm{~V}$ and $E_{\text {cell }}=0.35 \mathrm{~V}$ overlaps as the cell operates at the limiting average current density of $11,567 \mathrm{~A} / \mathrm{m}^{2}$ for the two cell voltages. It can be seen from Fig. 7(a) that the optimum porosity for $E_{\text {cell }}=0.50 \mathrm{~V}$ is much larger than that observed for $E_{c e l l}=0.35 \mathrm{~V}$. It is noted that the porosity for $E_{\text {cell }}=0.50 \mathrm{~V}$ increases from 0.77 to 0.93 whereas, the optimum porosity for $E_{\text {cell }}=$ $0.35 \mathrm{~V}$ increases from 0.16 to 0.66 . This behavior can be attributed to the fact that the reactant gases required for chemical reactions at high cell voltages are less than that consumed at low cell voltages and hence variation in the reactant gases concentration is also smaller along the channel for higher cell voltages. It can be seen that the local current density, for $E_{\text {cell }}=0.35$ and $0.20 \mathrm{~V}$, decreases along the channel at the near inlet region as the porosity increases relatively slower. Further along the length of the channel, with the increase in porosity the local current density increases owing to the compensatory effect of increase in porosity over decrease in the reactant gas concentration. The local current density decreases again at the channel outlet due as the reactant consumption dominates the effective current density. Whereas, for $E_{\text {cell }}=0.50 \mathrm{~V}$ the local current density decreases monotonically along the channel since the variation of the porosity is smaller and the effect of the decreasing species concentration dominates the local current density distribution along the entire channel. 
Figures 8(a) and (b) present the optimum porosity and local current density distribution, respectively, for $\Delta I / I_{\min }$ of $5 \%, 10 \%$ and $20 \%$, at $E_{\text {cell }}=0.35 \mathrm{~V}$. It can be seen in Fig. $8(\mathrm{a})$ that the optimum porosity distributions follow a similar trend for the values of $\Delta \mathrm{I} / \mathrm{I}_{\mathrm{min}}$ : the porosity starts with a low value around 0.15 , increases slowly for first one-third of the channel length followed by a steep increase in porosity value at the near outlet region. It is also noted that the porosity variation increases with increase in $\Delta I / I_{\min }$. The local current densities shown in Fig. 8(b) follow a similar trend as observed in Fig. 7(b). It is noted that larger the current density variation, the larger the average current density, due to the larger porosity owing to the need of higher transport rate of species to the catalyst sites. The optimum porosity and local current density distributions for $\Delta I / I_{\min }=5 \%, 10 \%$ and $20 \%$ and $E_{\text {cell }}=0.50 \mathrm{~V}$ are presented in Figs. $8(\mathrm{c})$ and $(\mathrm{d})$, respectively. The local porosity for $\Delta I / I_{\min }=10 \%$ shows smaller variation to that observed for $\Delta I / I_{\min }=5 \%$, with the high porosity values for $\Delta I / I_{\min }=10 \%$ all along the length. For larger allowable current density variation, the porosity can be larger to let more reactant species diffuse into the catalyst layer allowing higher variation, whereas for the smaller allowable current density variation, the porosity should be smaller to prevent the concentration variation as shown in Fig. 8(d). Comparing the porosity distributions for the same $\Delta I / I_{\min }$ at $E_{\text {cell }}=0.35 \mathrm{~V}$ [Fig. 8(a)] and $E_{\text {cell }}=0.50 \mathrm{~V}$ [Fig. 8(b)], it can be seen that the local porosity for $E_{\text {cell }}=0.50 \mathrm{~V}$ is larger than that for $E_{\text {cell }}=0.35 \mathrm{~V}$, which indicates that for high cell voltages the current density distribution can approach a uniform distribution with larger porosity values.

The effects of operating conditions on the optimum graded porosity distributions are discussed in Figs. 9-12. Figure 9 presents the optimum porosity and local current density distributions at $E_{\text {cell }}=0.35 \mathrm{~V}$ and $0.50 \mathrm{~V}$, for different cell temperatures, $T$. It can be seen from Figs. 9(a) and (c) that the optimum local porosity decreases with the increase in cell temperature. This behavior can be attributed to the increase in reaction rate with temperature 
leading to larger concentration variation along the channel. Therefore, the porosity starts at lower values at the inlet for higher temperatures, facilitating a uniform concentration distribution along the channel, as shown in Figs. 9(a) and (c). The local current density distributions of $E_{\text {cell }}=0.35 \mathrm{~V}$ for $T=353 \mathrm{~K}$ and $T=373 \mathrm{~K}$ follow a similar trend. However, the average current density for $T=373 \mathrm{~K}$ is lower than that for $T=353 \mathrm{~K}$ since increasing the temperature can accelerate the reactions speed but at a cost of lower oxygen mass flow rate and large membrane ionic resistance due to dry membrane resulting in smaller average current density at higher temperature. Whereas for $E_{\text {cell }}=0.50 \mathrm{~V}$, the average current density for $T=$ $353 \mathrm{~K}$ and $T=373 \mathrm{~K}$ are almost the same since for high cell voltages or low average current densities, the mass flow rate has little effect on the performance due to smaller species consumption.

Figure 10 shows the effect of operating pressure, $p$ (considered to be equal on the cathode and the anode sides), on the optimum porosity and local current density distributions for $0.35 \mathrm{~V}$ [Figs. 9(a) and (b)] and $0.50 \mathrm{~V}$ [Figs. 10(c) and (d)]. It can be seen from Fig. 10(a) that the effect of operating pressure on optimum porosity distribution for $E_{c e l l}=0.35 \mathrm{~V}$ is non-monotonic, while the local current density increases with increase in pressure for the length of channel simulated here. Increasing pressure increases species concentrations and accelerates the electrochemical reactions resulting in increased average current density. The optimum porosity distributions for different operating pressures show a similar trend for $E_{\text {cell }}=0.35 \mathrm{~V}$ with increase in porosity along the length of the flow. For higher voltage, $E_{\text {cell }}=0.50 \mathrm{~V}$ the optimum porosity for high pressures [Fig. 10(c)] tends to be closer to uniform distribution with large values, leading to large average current density [Fig. 10(d)], whereas that for low pressure the porosity has larger variation to approach the required current density variation, $10 \%$, leading to low average current density due to the reduced pressure and porosity. 
The effects of cathode mass flow rate on the optimum porosity and corresponding local current density distributions are presented in Fig. 11 for $0.35 \mathrm{~V}$ and $0.50 \mathrm{~V}$. The trend shows that for increase in the cathode mass flow rate the values of optimum porosity and local current density increases for both $E_{\text {cell }}=0.35 \mathrm{~V}$ and $0.50 \mathrm{~V}$. The decrease in cathode mass flow rate reduces the species concentration locally, which potentially leads to a larger concentration variation along the channel. Therefore, the optimum results for porosity distribution tends to show smaller values for porosity to prevent the fast reactions at inlet and provide a more uniform concentration distribution along the length of the channel in order to approach the required current density variation of $10 \%$, as shown in Figs. 11(a) and (c), resulting in smaller average current densities as shown in Figs. 11(b) and (d).

Figure 12 presents the optimum porosity and local current density distributions at $E_{c e l l}=$ $0.35 \mathrm{~V}$ for different values of relative humidity at cathode inlet, $R H_{c}$. It can be seen that the optimum porosity and local current density distributions both monotonically decrease with increasing cathode relative humidity. For a given operating temperature, pressure and mass flow rate, increase in $R H_{c}$ leads to decreased oxygen concentration which, in turn, leads to higher concentration variation along the length of the channel during the cell operation. Therefore, to keep the current density variation to within a desired level, the obtained optimum porosity variation decreases with increase of humidity so as to allow less oxygen into the catalyst site, thereby decreasing the average current density.

The results so far illustrated optimization results in which the cathode GDL porosity varied continuously following a power law (Eq. 13) along the length of the cell. Although a continuous porosity distribution mathematically provides the most flexibility to meet a desired uniformity of local current density variation, it is often convenient in practice to fabricate GDLs with discrete regions of piecewise constant porosity (Eq. 12). It is, therefore, of interest to assess the 
effectiveness of a piecewise constant porosity distribution vis-à-vis a continuous porosity variation. Figure 13(a) presents the optimum porosity variations based on a continuous profile and a piecewise constant profile, corresponding to the two optimization problems discussed in Section 3, for a cell voltage of $0.35 \mathrm{~V}$ and a desired current density uniformity of $20 \%$. Similar to the observations in Figs. 6-12, a non-monotonic variation in current density distribution along the length of the channel is observed in Fig. 13(b). It also noted that the lowest local current density occurs at the outlet of the channel, leading to an extremely high value of porosity distribution at the outlet, $\varepsilon_{3}=0.985$, while $\varepsilon_{1}=0.184$ and $\varepsilon_{2}=0.307$, which are very close to the average values of the continuous porosity in the corresponding regions: 0.181 and 0.299 , respectively. The average porosity values for discrete and continuous distributions are 0.492 and 0.384 , respectively, and the average current densities for discrete and continuous porosity distributions are $12,469 \mathrm{~A} / \mathrm{m}^{2}$ and $12,224 \mathrm{~A} / \mathrm{m}^{2}$. The comparison in Fig. 13 suggests that the cell performance and optimum porosity distribution are similar for the continuous or discrete porosity distributions, and that a discrete variation of porosity may be used in practice just as effectively.

The comparison of the measured experimental data from the fuel cell with uniform porosity and with discrete porosity is presented in Fig. 14. The solid lines represent the local current distribution along the channel for the uniform porosity distribution $(\varepsilon=0.53)$ for different current and the dashed lines represent the current distribution for the discrete porosity distribution with $\varepsilon_{1}=0.25, \varepsilon_{2}=0.53$ and $\varepsilon_{3}=0.79$. It can be seen that for uniform porosity distribution, the current density at first increases followed by decrease in the current density going forward along the length of the channel. The membrane is relatively dry at the channel inlet, which leads to a larger membrane resistance and lower current at the inlet. With increase in $y$, along the length of the channel, the oxygen concentration decreases due to the reaction 
consumption resulting in decrease in local current density along the channel. The variation in the local current along the channel increases with increase in average current, which is consistent with that observed in Fig. 6. For the piecewise constant porosity distribution, the fuel cell performance is improved and the variation of the local current along the channel is greatly reduced. Increasing the porosity along the channel ensures a uniform gas distribution into the catalyst sites and hence improvement in the current distribution.

Figure 15 shows a comparison of experimental data with numerical results for a piecewise constant porosity distribution with values of $\varepsilon_{1}=0.25, \varepsilon_{2}=0.53$ and $\varepsilon_{3}=0.79$. Figure $14(\mathrm{a})$ presents the comparison of normalized current density distribution along the channel at $E_{c e l l}=$ $0.67 \mathrm{~V}$. It can be seen that the variation in the local current density from the experiment is around $10 \%$, while that from the corresponding numerical simulation is around $5 \%$, which is close to the experimental data. The comparison of the normalized local current density for $E_{c e l l}$ $=0.35 \mathrm{~V}$ is shown in Fig. 15(b). The distribution from numerical simulation predicts a variation of $25 \%$, while a $15 \%$ variation is measured in the experiments. It is implied that the discrete porosity distribution used in the experiments improves the current density distribution at $E_{\text {cell }}$ $=0.35 \mathrm{~V}$ compared to that obtained with uniform porosity. It is to be noted here that the discrete distribution used in the experiments is not the optimum discrete porosity distribution for $E_{c e l l}=$ $=0.35 \mathrm{~V}$ and leads to a larger variation of $25 \%$. The optimum piecewise constant porosity distribution for $E_{\text {cell }}=0.35 \mathrm{~V}$, and a $15 \%$ uniformity in the current density variation, is illustrated in Fig. 16.

Figure 16(a) shows the optimum continuous and discrete graded porosity distributions, represented by continuous and step solid lines respectively, compared with the discrete porosity values used in the experiment: $0.25,0.53$, and 0.79 (dashed lines). The optimum discrete porosities are $\varepsilon_{1}=0.20, \varepsilon_{2}=0.33$ and $\varepsilon_{3}=0.98$. Since the lowest oxygen concentration 
occurs at the outlet of the channel, the predicted porosity there is extremely high in order to enhance oxygen transport. The average values for the optimum continuous porosity distribution at the three different regions are $0.21,0.37$ and 0.73 , which are very close to the optimum piecewise constant values, except in the third region. The porosities used in the experiments follow a similar trend as seen for numerical predictions and the corresponding current density distributions are presented in Fig. 16(b). It can be seen that the normalized local current density distributions for the numerical simulations and experiments are very close to each other, and show around 15\% variation, indicating that the current density distribution is improved by using graded porosity distribution along the channel.

The results presented in this paper provide a comprehensive analysis of the effects of graded porosity profiles on the variation of local current density along the length of a PEM fuel cell. The graded porosity GDLs were designed in this study for maximizing the power density, although the methodology for obtaining the optimum porosity distribution may be readily applied to other performance criteria. Future work could include the lateral (in-plane) variation in GDL porosity using a comprehensive three-dimensional model. The graded porosity GDL could be used to find the optimized operating parameters for effective water management or transient operations as studied in [33] using the two phase approach for varying GDL properties as demonstrated in $[34,35]$. The porosity in GDL can also be optimized to limit the residual stresses arising due to plastic deformation during transient operation. While this study considered tailoring the electrochemical reaction along the length of the fuel cell through varying the porosity distribution, a similar approach on varying the catalyst loading along the fuel cell also produces the desired uniformity in the current density, as presented in [36]. The graded approach could also be studied for air breathing PEM fuel cells that do not depend on forced convection for air inlet [37]. The combined effects of simultaneously varying the catalyst 
loading and the GDL porosity may be considered in a future work for optimizing pertinent technoeconomic criteria.

\section{Conclusions}

The influence of functionally graded porosity in the cathode GDL, on the local current density distribution was studied with the goal of developing optimal porosity variation so as to minimize the current density variation along the cell, while maximizing the power density. The experimental work validated the numerical results and demonstrated that the use of optimal porosity distribution along the channel decreases the current density variation while maintaining the same average current density compared to that from uniform porosity distribution. The variation in current density was found to reduce from $102 \%$ to $10 \%$ for $E_{c e l l}=$ $0.35 \mathrm{~V}$ and from $12 \%$ to $5 \%$ for $E_{c e l l}=0.50 \mathrm{~V}$, by using optimized porosity variations at cathode. Operating parameters were found to have significant effect on the porosity and current distribution. The optimum porosity was found to decrease with increase in temperature, and increase with increase with cell voltage, uniformity criterion, cathode mass flow rate and cathode relative humidity, whereas a non-monotonic relationship was observed with the

changes in the operating pressure. Optimized piecewise constant porosity variation and optimized continuous porosity variation of the cathode GDL were both found to have similar effects on the local current density distribution, suggesting that it may be sufficient to use a piecewise constant porosity GDL in practice. The studies presented in this paper offer opportunities for improving the performance and durability of PEM fuel cells.

\section{Acknowledgements}


The authors gratefully acknowledge the support for the work from the U.S. Army RDECOM through Contract no. DAAB07-03-3-K-415.

\section{Nomenclature}

$D_{i, r e f} \quad$ reference diffusivity of species i $\left[\mathrm{m}^{2} / \mathrm{s}\right]$

$D_{i}^{e f f} \quad$ effective diffusivity of species i in the porous media $\left[\mathrm{m}^{2} / \mathrm{s}\right]$

$E_{\text {cell }} \quad$ cell voltage [V]

$\hat{\mathrm{i}}, \hat{\mathrm{j}} \quad$ unit vectors in $\mathrm{x}$ and $\mathrm{y}$-directions

$i_{s} \quad$ solid phase current density $\left[\mathrm{A} / \mathrm{m}^{2}\right]$

$i_{m} \quad$ membrane phase current density $\left[\mathrm{A} / \mathrm{m}^{2}\right]$

$i_{y} \quad$ local current density in $y$-direction $\left[\mathrm{A} / \mathrm{m}^{2}\right]$

$i \quad$ local current density $\left[\mathrm{A} / \mathrm{m}^{2}\right]$

$I_{\text {ave }} \quad$ average current density $\left[\mathrm{A} / \mathrm{m}^{2}\right]$

$\vec{\imath}_{\text {local }}$ local current density vector $\left[\mathrm{A} / \mathrm{m}^{2}\right]$

$\Delta I \quad$ current density variation $\left[\mathrm{A} / \mathrm{m}^{2}\right]$

$k \quad$ permeability of gas diffusion layer $\left[\mathrm{m}^{2}\right]$

$m_{a}$ anode mass flow rate $[\mathrm{kg} / \mathrm{s}]$

$m_{c} \quad$ cathode mass flow rate $[\mathrm{kg} / \mathrm{s}]$

$p \quad$ pressure $[\mathrm{Pa}]$

$P_{d} \quad$ power density $\left[\mathrm{W} / \mathrm{cm}^{2}\right]$

$R H \quad$ relative humidity

$S_{C} \quad$ the source term of mass conservation equation $\left[\mathrm{kg} /\left(\mathrm{m}^{3} . \mathrm{s}\right)\right]$

$S_{V}$ the source term of momentum conservation equation $\left[\mathrm{N} / \mathrm{m}^{3}\right]$ 
$S_{i} \quad$ the source term of species conservation equation $\left[\mathrm{kg} /\left(\mathrm{m}^{3} . \mathrm{s}\right)\right]$

$S_{j} \quad$ the source term of potential equations $\left[\mathrm{A} / \mathrm{m}^{3}\right]$

$T$ temperature $[\mathrm{K}]$

$\vec{V} \quad$ superficial velocity vector $[\mathrm{m} / \mathrm{s}]$

$V \quad$ volume $\left[\mathrm{cm}^{2}\right]$

$x$ position coordinate across the cell thickness/the membrane

$y_{i} \quad$ mass fraction of species $\mathrm{i}$

$y \quad$ position coordinate along the channel

$\varepsilon \quad$ porosity of gas diffusion layer

$\varepsilon^{e f f} \quad$ effective porosity

$\rho \quad$ fluid density $\left[\mathrm{kg} / \mathrm{m}^{3}\right]$

$\boldsymbol{\tau} \quad$ the stress tensor $\left[\mathrm{kg} / \mathrm{m}^{2} \cdot \mathrm{s}^{2}\right]$

$\sigma_{m}^{e f f}$ effective membrane conductivity in porous media [1/(ohm.m)]

$\sigma_{s}^{e f f}$ electrical conductivity of the solid material [1/(ohm.m)]

$\phi_{s} \quad$ solid phase potential [V]

$\phi_{m} \quad$ membrane phase potential [V]

\section{Subscripts and Superscripts}

$\begin{array}{ll}\text { a anode } & \\ \text { ave average } \\ c \quad \text { cathode } \\ \text { ref reference } \\ m \text { membrane phase }\end{array}$




$$
\begin{array}{cl}
\min & \text { minimum } \\
\text { max } & \text { maximum } \\
i & \text { species } \\
s & \text { solid phase } \\
\text { eff } & \text { effective value }
\end{array}
$$

\section{References}

[1] Y. Zhang, A. Mawardi, R. Pitchumani, Effects of Operating Parameters on the Uniformity of Current Density Distribution in Proton Exchange Membrane Fuel Cells, Journal of Fuel Cell Science and Technology, 3(4) (2006) 464-476,.

[2] A. Verma, R. Pitchumani, Influence of membrane properties on the transient behavior of polymer electrolyte fuel cells, Journal of Power Sources, 268(5) (2014) 733-743 .

[3] W. Schmittinger, V. Ardalan, A review of the main parameters influencing long-term performance and durability of PEM fuel cells, Journal of Power Sources 180(1) (2008) 1-14.

[4] J. Wu, X.Z. Yuan, J.J. Martin, H. Wang, J. Zhang, J. Shen, S. Wu, W. Merida. A review of PEM fuel cell durability: degradation mechanisms and mitigation strategies, Journal of Power Sources 184(1) (2008) 104-119.

[5] A. Verma, R. Pitchumani, Investigation of Mechanical Behavior of Membrane in Polymer Electrolyte Fuel Cells Subject to Dynamic Load Changes, Journal of Fuel Cell Science and Technology 11(3) (2014) 031009 (9 pages)

[6] A. Verma, R. Pitchumani, Effects of operating parameters on the transient response of proton exchange membrane fuel cells subject to load changes, International Journal of Hydrogen Energy, 39(33) (2014)19024-19038,

[7] J. Stumper, S.A. Campbell, D.P. Wilkinson, M.C. Johnson, M. Davis, In-situ methods for the 
determination of current distributions in PEM fuel cells, Electrochimica Acta, 43(24) (1998)3773-3883.

[8] M.M. Mench, C.Y. Wang, M. Ishikawa, In situ current distribution measurements in polymer electrolyte fuel cells. Journal of the Electrochemical Society, 150(8) (2003) A1052A1059.

[9] H. Sun, G. Zhang, L. Guo, H. Liu, A novel technique for measuring current distributions in PEM fuel cells, Journal of Power Sources, 158 (2006) 326-332.

[10] D. Natarajan, T. Nguyen, Effect of electrode configuration and electronic conductivity on current density distribution measurements in PEM fuel cells, Journal of Power Sources, 135 (2004) 95-109.

[11] S.J. Cleghorn, C.R. Drouin, M.S. Wilkinson, A printed circuit board approach to measuring current distribution in a fuel cell, Journal of Applied Electrochemistry, 28 (1998) 663-672.

[12] D. Brett, S. Atkins, N. Brandon, V. Vesovic, N. Vasileiadis, A. Kucernak, Measurement of the current distribution along a single flow channel of a solid polymer fuel cell, Electrochem. Commun. 3 (2001) 628-632.

[13] M. Noponen, T. Mennola, M. Mikkola, T. Hottinen, and P. Lund, Measurement of current density distribution in a free-breathing PEMFC, Journal of Power Sources, 106 (2002) 304312.

[14] T. Hottinen, O. Himanen, P. Lund, Effect of cathode structure on planar free breathing PEMFC, Journal of Power Sources, 138 (2004) 205-210.

[15] Ch. Wieser, A. Helmbold, and E. Gzow, A new technique for two-dimensional current distribution measurements in electrochemical cells, Journal of Applied Electrochemistry, $30,803-807,2000$

[16] D. Candusso, J.P. Poirot-Crouvezier, B. Bador, E. Rullie, R. Soulier, and J.Y. Voyant, 
Determination of current density distribution in proton exchange membrane fuel cells, The European Physical Journal of Applied Physics, 25 (2004) 67-74,.

[17] S.A. Freunberger, M. Reum, J. Evertz, A. Wokaun, F.N. Büchi, Measuring the Current Distribution in PEFCs with Sub-Millimeter Resolution I. Methodology, Journal of Electrochemical Society, 153 (2006) A2158-2165.

[18] L. Wang, H. Liu, Separate measurement of current density under the channel and the shoulder in PEM fuel cells, Journal of Power Sources, 180(1) (2008) 365-372.

[19] D. Gerteisen, N. Zamel, C. Sadeler, F. Geiger, V. Ludwig, C. Hebling, Effect of operating conditions on current density distribution and high frequency resistance in a segmented PEM fuel cell, International Journal of Hydrogen Energy, 37(9) (2012) 7736-7744.

[20] L. Song, L. Hongtan, Direct measurement of current density under land and two channels in PEM fuel cells with interdigitated flow fields, International Journal of Hydrogen Energy, 39(17) (2014) 9440-9446.

[21] P.C. Sui, N. Djilali, Analysis of coupled electron and mass transport in the gas diffusion layer of a PEM fuel cell, Journal of Power Sources, 161 (2006) 294-300.

[22] S. Shimpalee, S. Greenway, D. Spuckler, and J.W. Van Zee, Predicting water and current distributions in a commercial-size PEMFC, Journal of Power Sources, 135 (2004) 79-87.

[23] T. Araki, H. Koori, T. Taniuchi, K. Onda, Simulation of the current density distribution for a PEMFC by using measured eletrochemical and physical properties of the membrane, Journal of Power Sources, 152 (2005) 60-66.

[24] H.J. Dong, K.N. Kim, S.M. Baek, J.H. Nam, The effect of relative humidity of the cathode on the performance and the uniformity of PEM fuel cells, International Journal of Hydrogen Energy, 36(19) (2011) 12499-12511.

[25] V. Guran, R. Barbir, and H. Liu, An Analytical Solution of a Half-Cell Model for PEM Fuel 
Cells, Journal of Electrochemical Society, 147 (2000) 2468-2477.

[26] H.S. Chu, C. Yeh, and F. Chen, Effects of porosity change of gas diffuser on performance of proton exchange membrane fuel cell, Journal of Power Sources, 123 (2003)1-9.

[27] W.M. Yan, C.Y. Soong, F. Chen, and H.S. Chu, Effects of flow distributor geometry and diffusion layer porosity on reactant gas transport and performance of proton exchange membrane fuel cells, Journal of Power Sources, 125 (2004) 27-39,.

[28] Z. Zhan, J. Xiao, D. Li, M. Pan and R. Yuan, Effects of porosity distribution variation on the liquid water flux through gas diffusion layers of PEM fuel cells, Journal of Power Sources, 160 (2006) 1041-1048.

[29] C.H. Min, Y.L. He, X.L. Liu, B.H. Yin, W. Jiang, W.Q. Tao, Parameter sensitivity examination and discussion of PEM fuel cell simulation model validation Part II: Results of sensitivity analysis and validation of the model, Journal of Power Sources, 160 (2006)374385.

[30] H. Tang, S. Wang, M. Pan, R. Yuan, Porosity-graded micro-porous layers for polymer electrolyte membrane fuel cells." Journal of power sources 166(1) (2007) 41-46.

[31] R Schweiss, M. Steeb, P.M. Wilde, T Schubert. Enhancement of proton exchange membrane fuel cell performance by doping microporous layers of gas diffusion layers with multiwall carbon nanotubes. Journal of Power Sources, 220 (2012) 79-83.

[32] R.B. Bird, W.E. Stewart, and E.N. Lightfoot, Transport Phenomena, John Wiley and Sons, New York, NY, 1960.

[33] A. Verma and R. Pitchumani, Analysis and optimization of transient response of polymer electrolyte fuel cells, Journal of Fuel Cell Science and Technology, 12(1) (2015) 011005, 10 pages.

[34] Y. Zhang, A. Smirnova, A. Verma and R. Pitchumani, Design of Proton Exchange 
Membrane Fuel Cell with Variable Catalyst Loading, Journal of Power Sources, 291(2015) $46-57$.

[35] Y. Wang, Ken S. Chen, Jeffrey Mishler, Sung Chan Cho, Xavier Cordobes Adroher, A Review of Polymer Electrolyte Membrane Fuel Cells: Technology, Applications, and Needs on Fundamental Research, Applied Energy 88 (2011) 981-1007

[36] Y. Wang and Ken S. Chen, Effect of Spatially-Varying GDL Properties and Land Compression on Water Distribution in PEM Fuel Cells, J. Electrochem. Soc. 158 (11) (2011) B1292-B1299

[37] Y. Zhang and R. Pitchumani, Numerical studies on air-breathing proton exchange membrane (PEM) fuel cell, Journal of Power Sources, 50(23-24) (2007) 4698-4712 2007. 


\section{Figure Captions}

Figure 1 Schematic illustration of a typical PEM fuel cell configuration and its working principle.

Figure 2 Schematic of a two-dimensional section of a PEM fuel cell as considered in the numerical models and the associated boundary conditions.

Figure 3 Schematic illustration of the steps in the optimization process.

Figure 4 (a) Photograph of a PEM fuel cell with segmented cathode current collector; (b) the exploded view of the layers inside the PEM fuel cell; and (c) measurement equipments in the testing system.

Figure 5 Schematic illustration of variable porosity GDL.

Figure 6 Optimum continuous porosity variation and local current density distributions compared with those from the uniform porosity distributions: (a) porosity comparison at $E_{\text {cell }}=0.35 \mathrm{~V}, \Delta I / I_{\min }=10 \%$; (b) local current density comparison at $E_{\text {cell }}=0.35 \mathrm{~V}, \Delta I / I_{\text {min }}=10 \%$; (c) porosity comparison at $E_{\text {cell }}=0.50 \mathrm{~V}, \Delta I / I_{\min }=5 \%$; and (d) local current density comparison at $E_{\text {cell }}=0.50 \mathrm{~V}, \Delta I / I_{\min }=5 \%$.

Figure 7 Effects of cell voltage on (a) optimum continuous porosity variation and (b) corresponding local current density distribution for $\Delta I / I_{\min }=10 \%$

Figure 8 Effects of uniformity criterion on (a) optimum continuous porosity variation and (b) corresponding local current density distribution at $E_{\text {cell }}=0.35 \mathrm{~V}$.

Figure 9 Effects of operating temperature on (a) optimum continuous porosity variation at $E_{\text {cell }}=0.35 \mathrm{~V} ;(\mathrm{b})$ corresponding local current density distribution at $E_{\text {cell }}=0.35 \mathrm{~V}$; (c) optimum continuous porosity variation at $E_{\text {cell }}=0.50 \mathrm{~V}$; and (d) optimum local current density distribution at $E_{\text {cell }}=0.50 \mathrm{~V}$.

Figure 10 Effects of operating pressure on (a) optimum continuous porosity variation at $E_{c e l l}=$ 
$0.35 \mathrm{~V}$; (b) optimum local current density distribution at $E_{\text {cell }}=0.35 \mathrm{~V}$; (c) optimum continuous porosity variation at $E_{\text {cell }}=0.50 \mathrm{~V}$; and (d) optimum local current density distribution at $E_{\text {cell }}=0.50 \mathrm{~V}$.

Figure 11 Effects of cathode mass flow rate on (a) optimum continuous porosity variation at $E_{\text {cell }}=0.35 \mathrm{~V} ;(\mathrm{b})$ optimum local current density distribution at $E_{\text {cell }}=0.35 \mathrm{~V}$; (c) optimum continuous porosity variation at $E_{\text {cell }}=0.50 \mathrm{~V}$; and (d) optimum local current density distribution at $E_{\text {cell }}=0.50 \mathrm{~V}$.

Figure 12 Effects of cathode relative humidity on (a) optimum continuous porosity variation; and (b) optimum local current density distribution, for $E_{\text {cell }}=0.35 \mathrm{~V}$.

Figure 13 (a) Comparison of optimum piecewise constant and continuous porosity variations at $E_{\text {cell }}=0.35 \mathrm{~V}, \Delta I / I_{\min }=20 \%$; and (b) comparison of corresponding local current density distributions at $E_{\text {cell }}=0.35 \mathrm{~V}, \Delta I / I_{\min }=20 \%$.

Figure 14 Comparison of the measured local current distributions for a constant porosity value of 0.53 (solid lines) with those for a piecewise constant porosity variation of $0.25,0.53$ and 0.79 (dashed lines), for three different values of the average current.

Figure 15 Comparison of the numerical and experimental data of the normalized local current density distribution for a piecewise constant porosity variation of $0.25,0.53$, and 0.79 , at (a) $E_{\text {cell }}=0.67 \mathrm{~V}$ and (b) $E_{\text {cell }}=0.35 \mathrm{~V}$.

Figure 16 Comparison of (a) the optimum porosity variations and (b) the corresponding normalized local current density distribution for $E_{\text {cell }}=0.35 \mathrm{~V}$. 


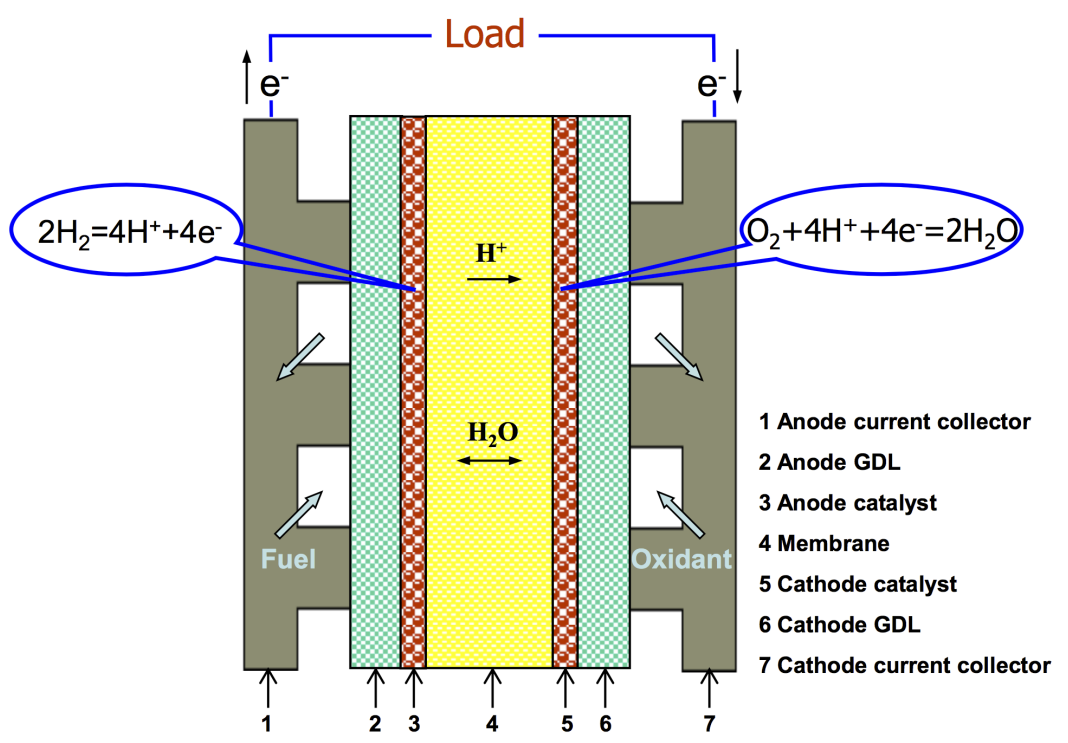

Figure 1: Zhang, Verma and Pitchumani 


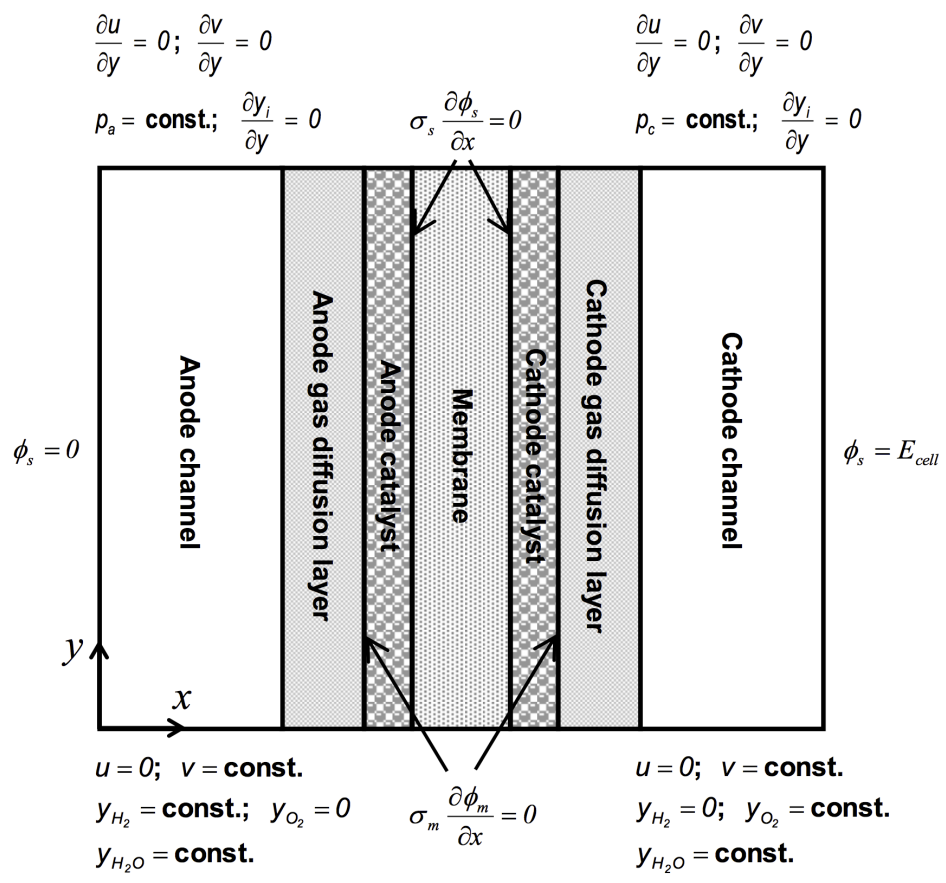

Figure 2: Zhang, Verma and Pitchumani 


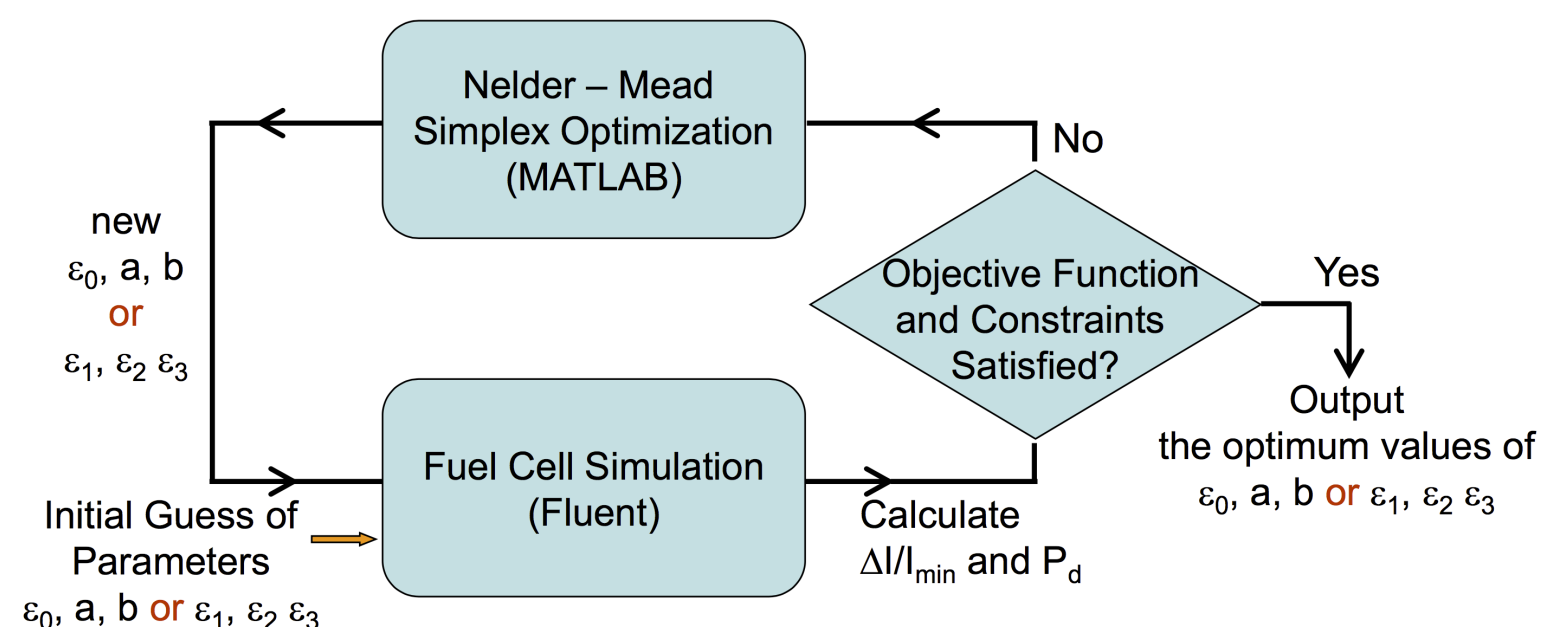

Figure 3: Zhang, Verma and Pitchumani 

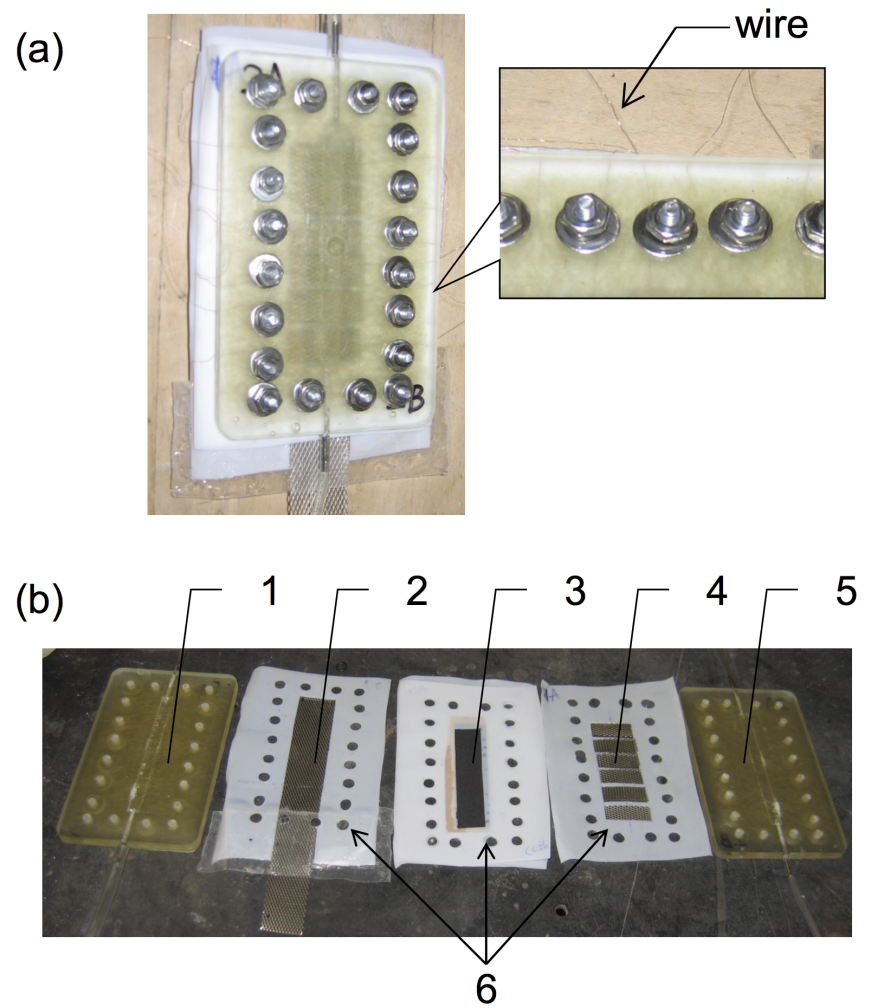

(c)

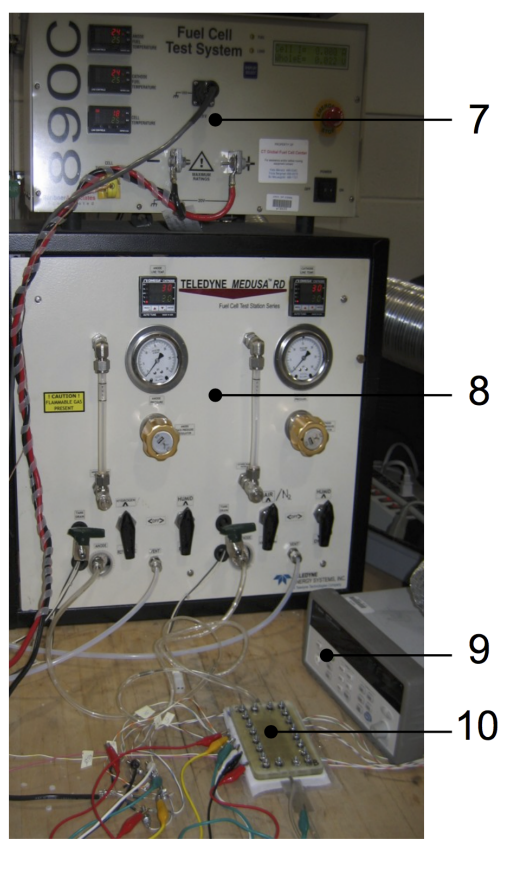

Figure 4: Zhang, Verma and Pitchumani 


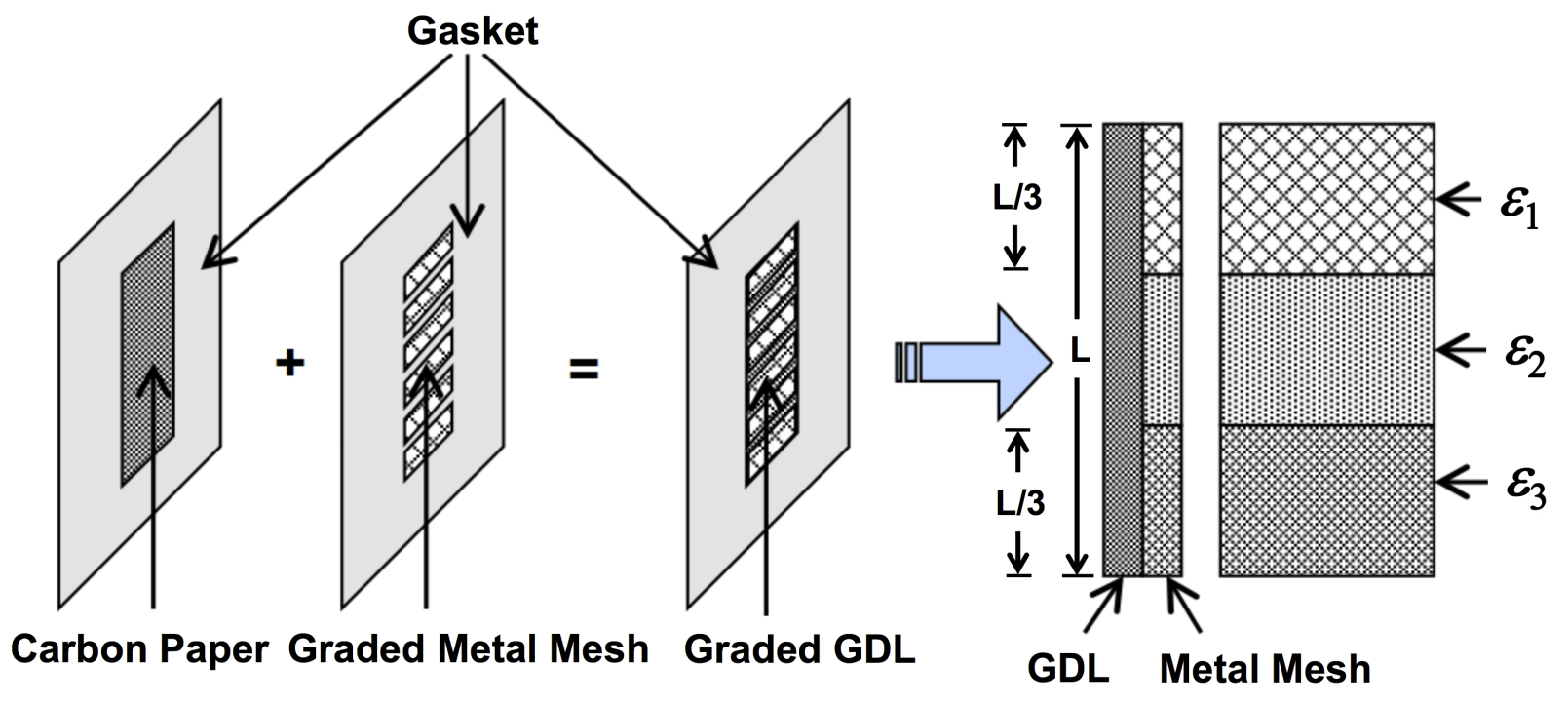

Figure 5: Zhang, Verma and Pitchumani 

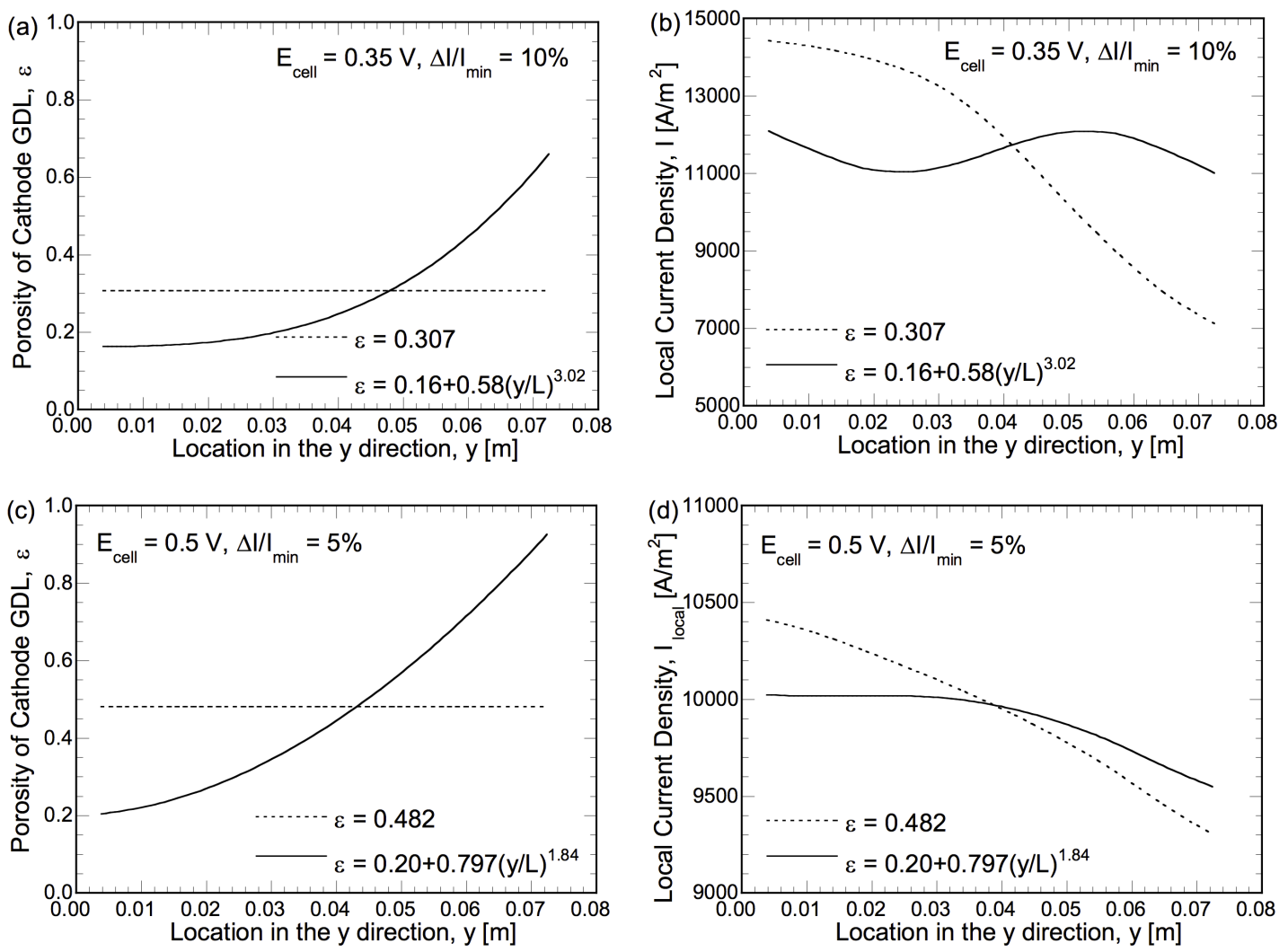

Figure 6: Zhang, Verma and Pitchumani 

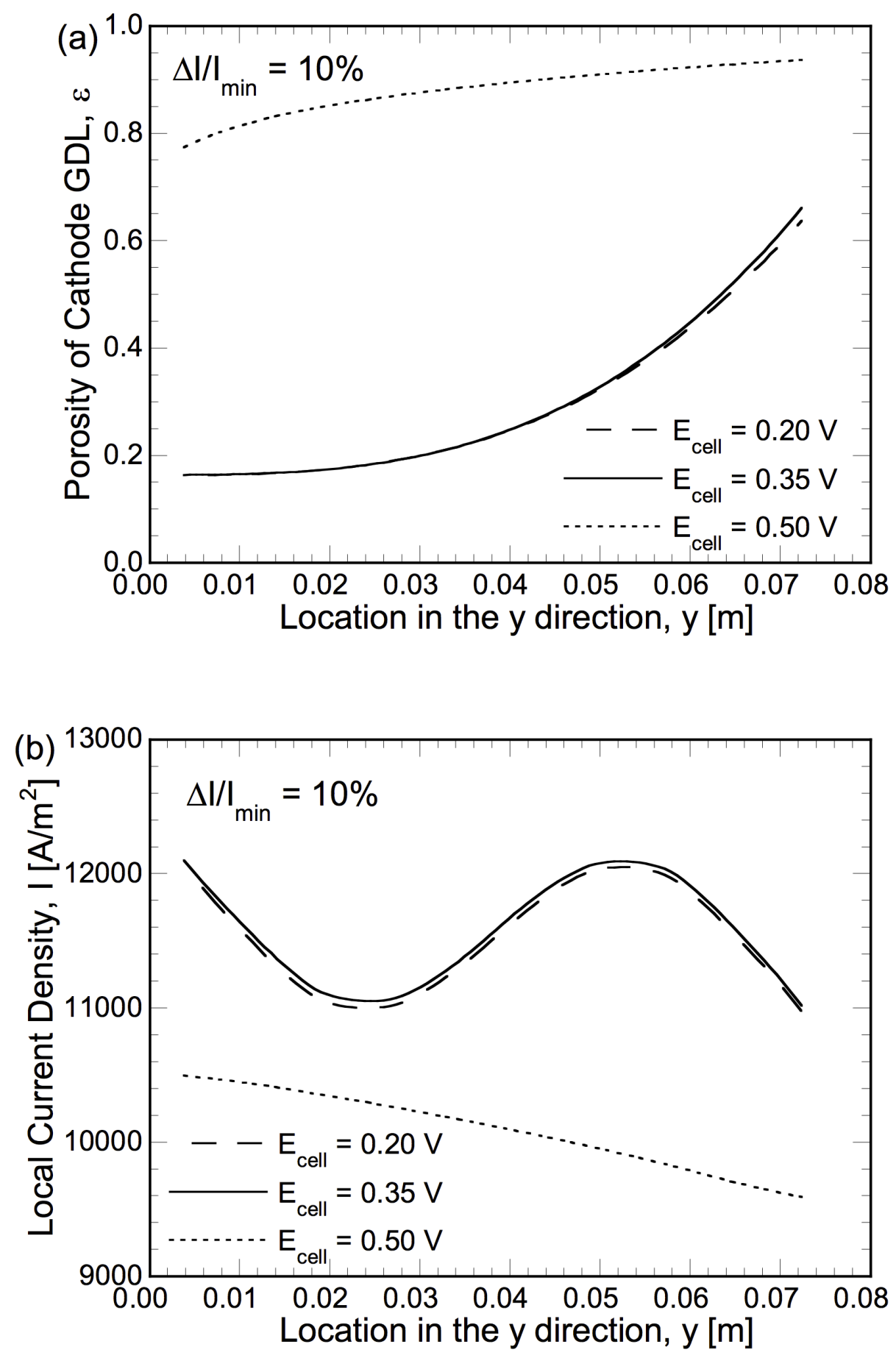

Figure 7: Zhang, Verma and Pitchumani 

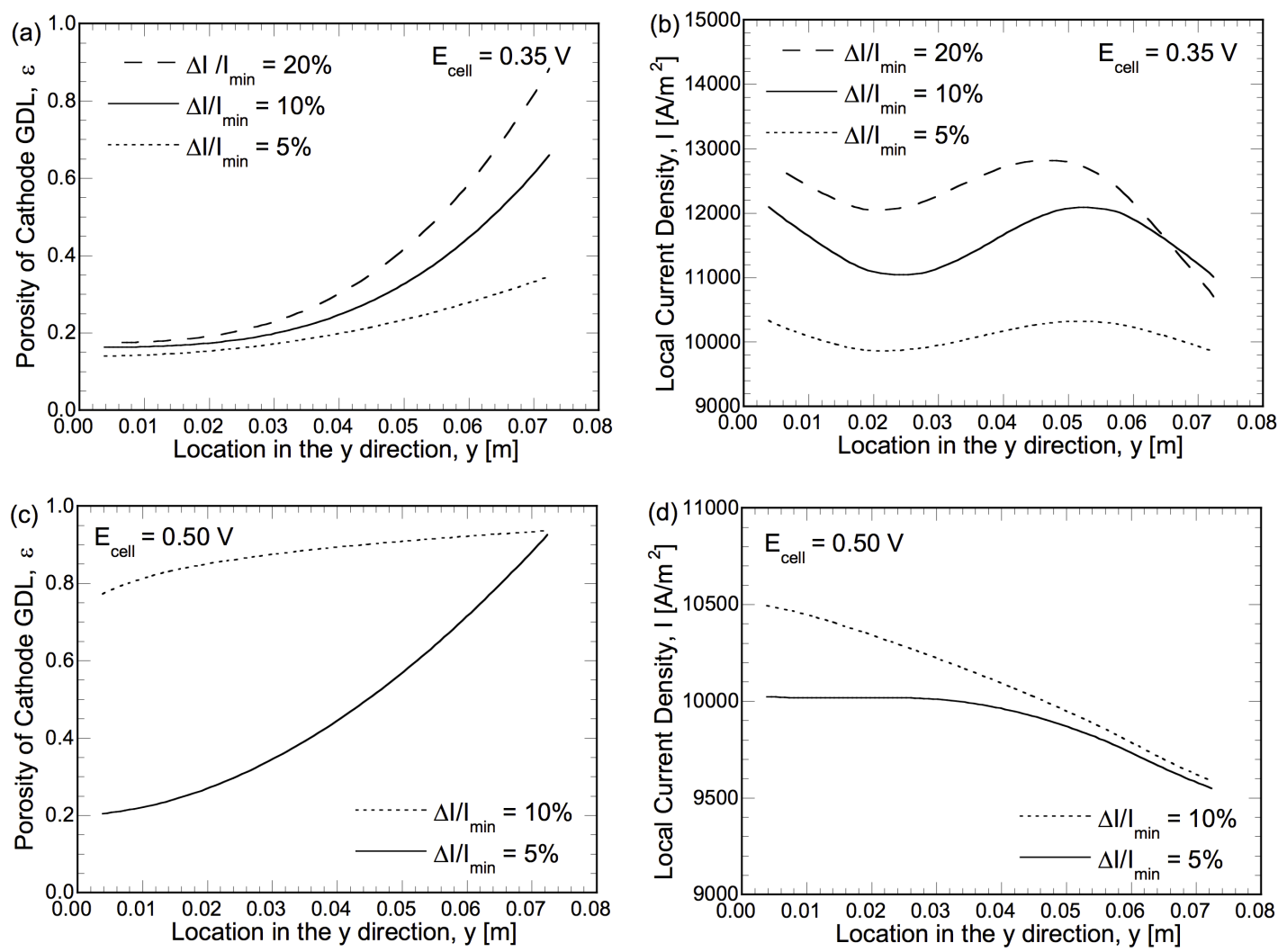

Figure 8: Zhang, Verma and Pitchumani 

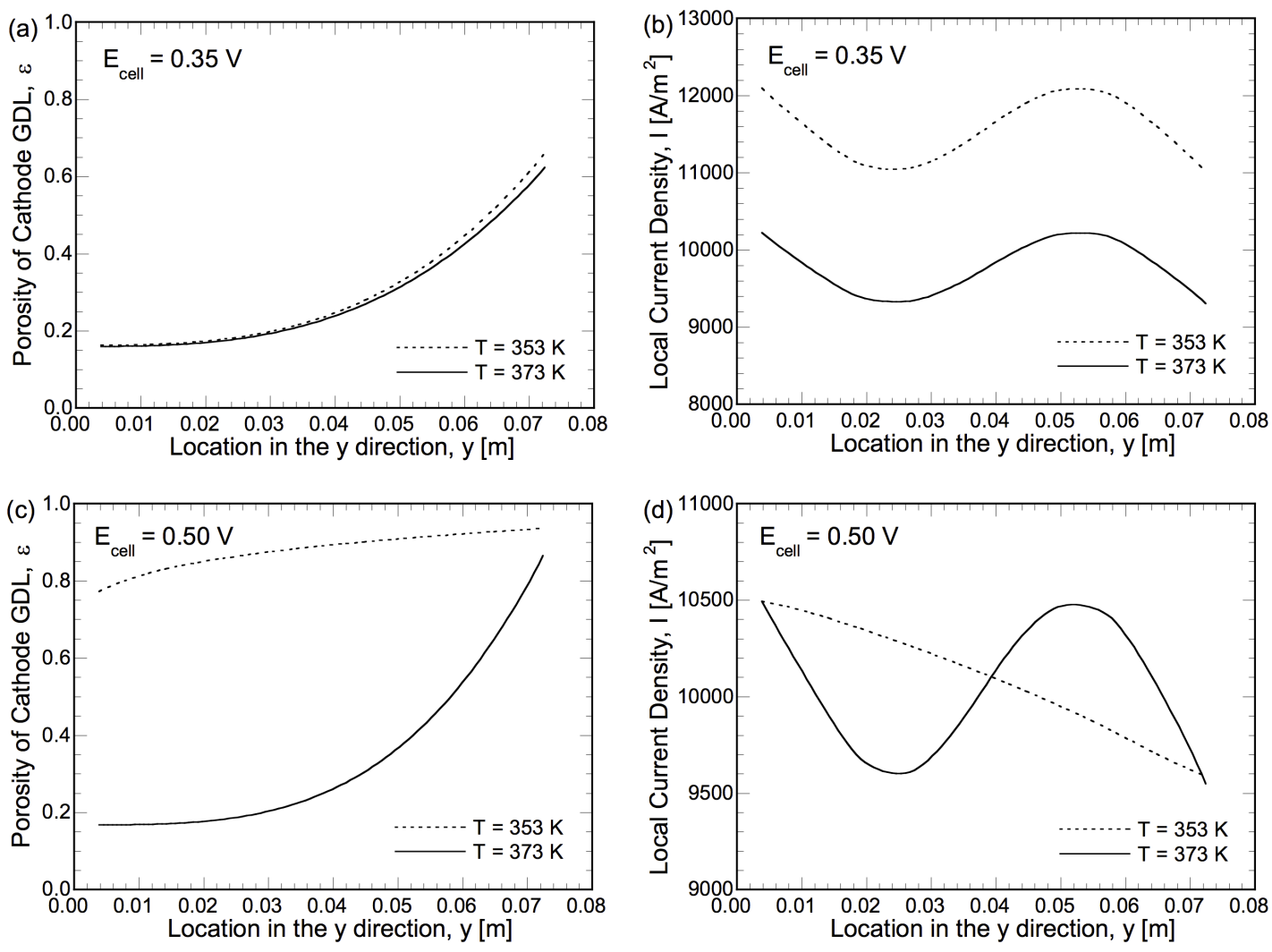

Figure 9: Zhang, Verma and Pitchumani 

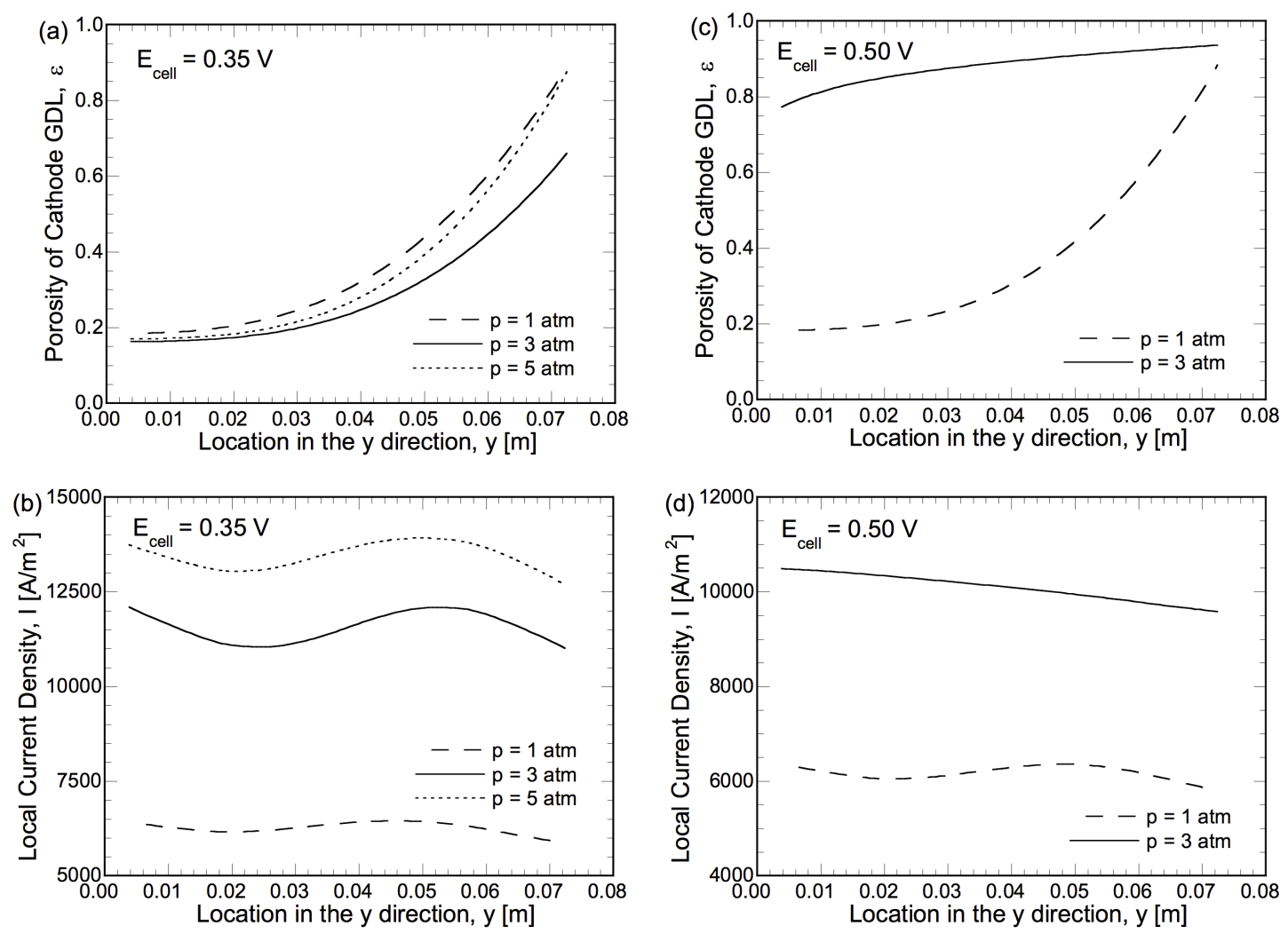

Figure 10: Zhang, Verma and Pitchumani 

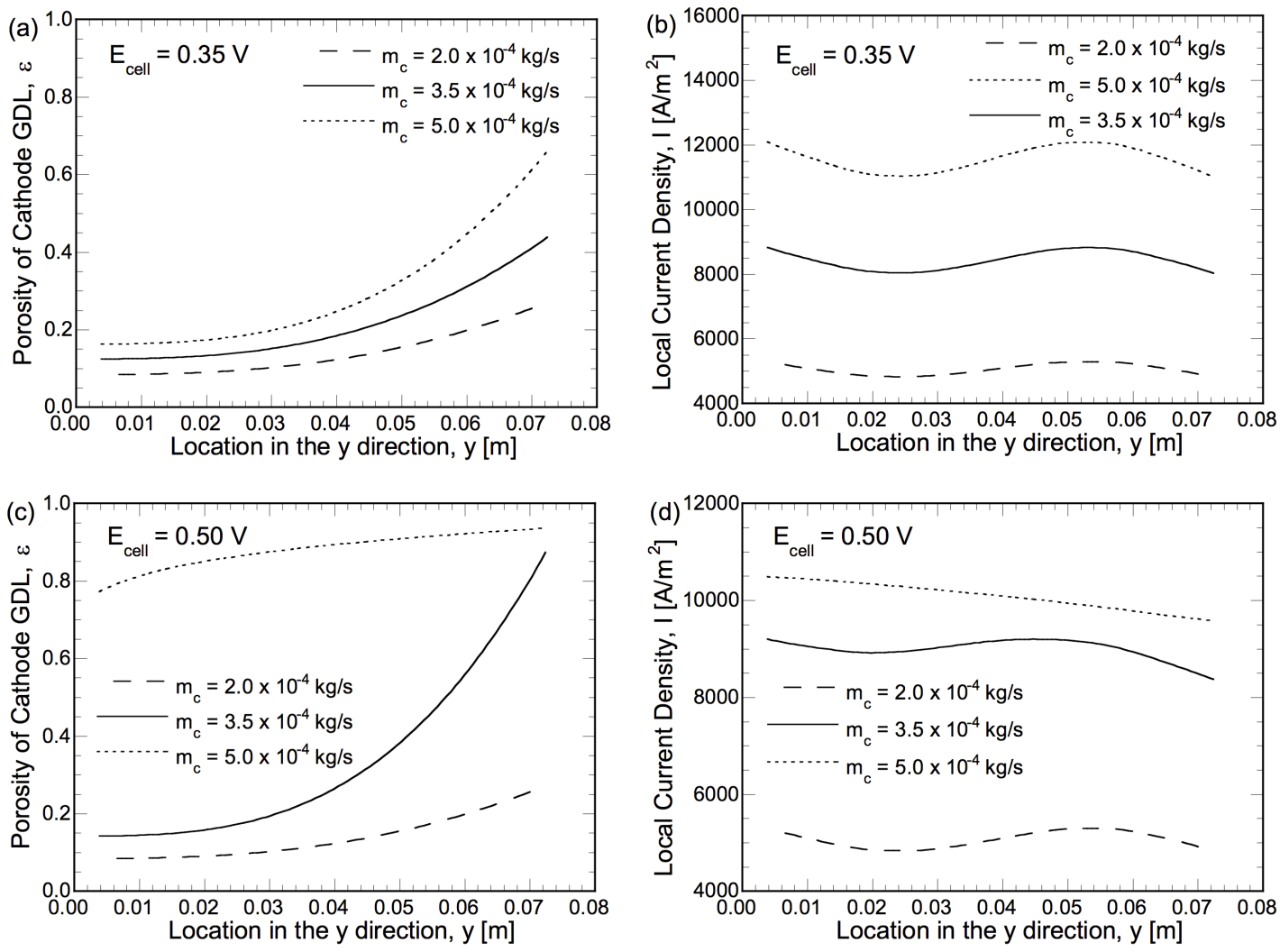

Figure 11: Zhang, Verma and Pitchumani 

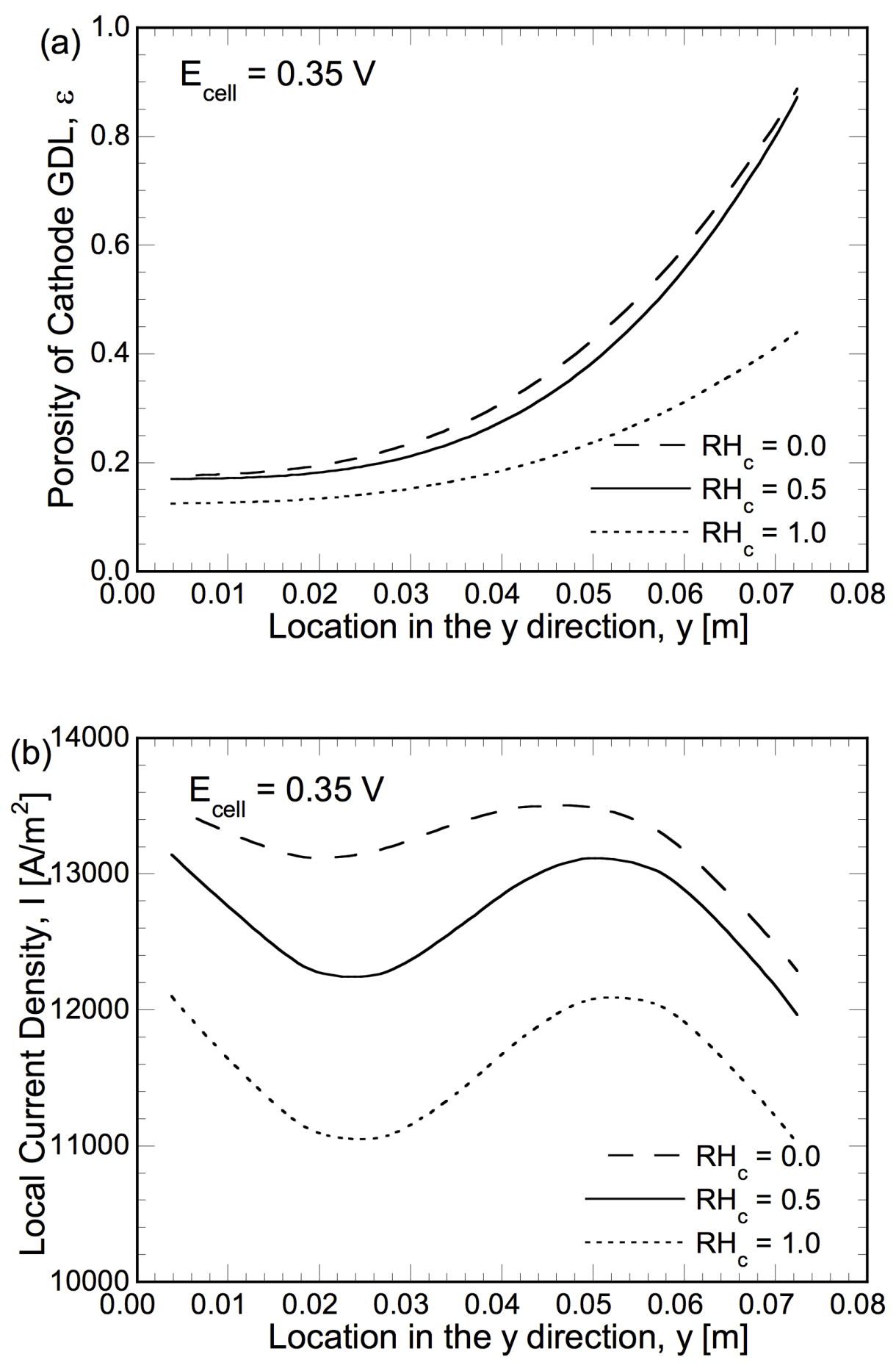

Figure 12: Zhang, Verma and Pitchumani 

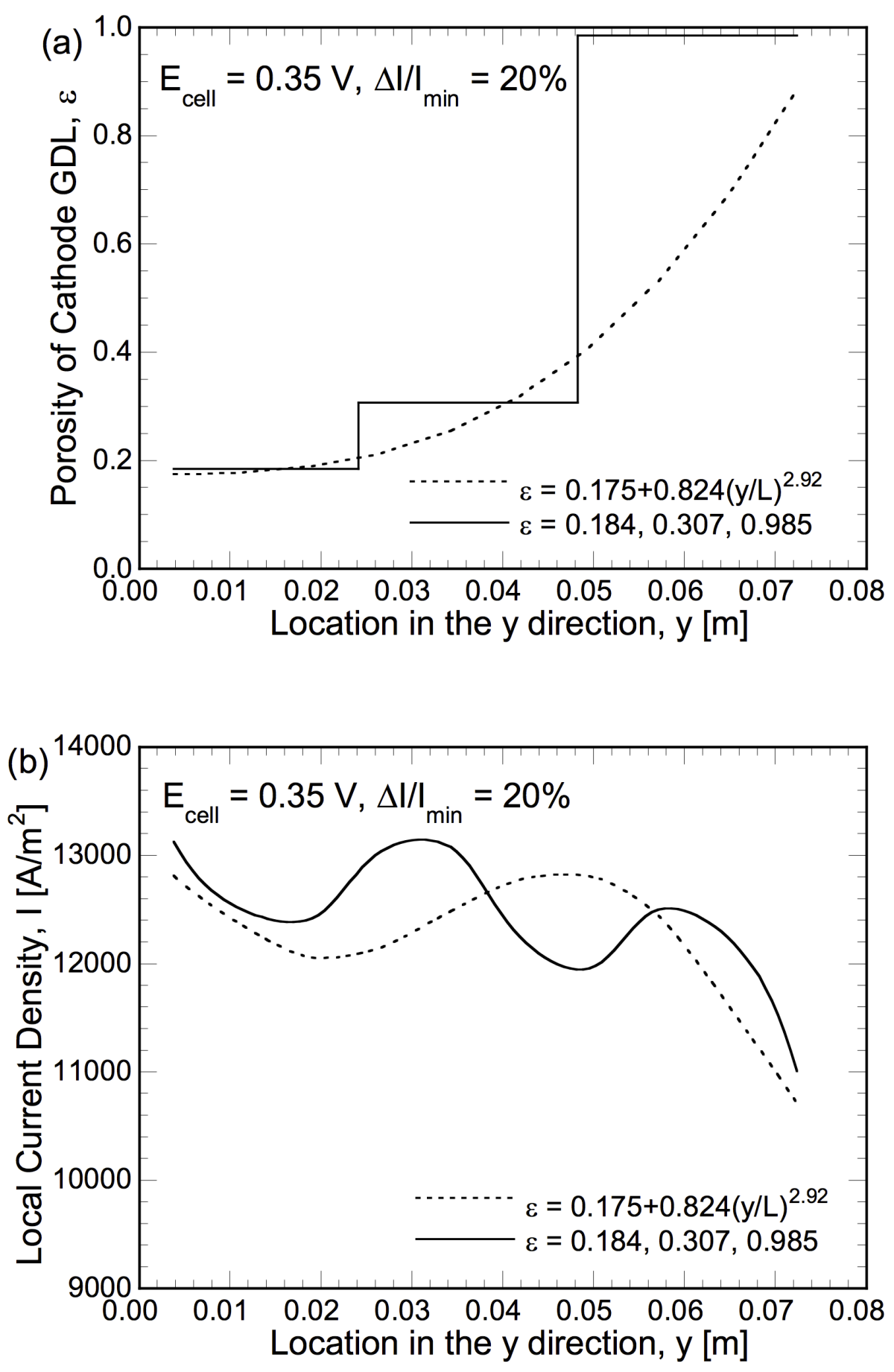

Figure 13: Zhang, Verma and Pitchumani 


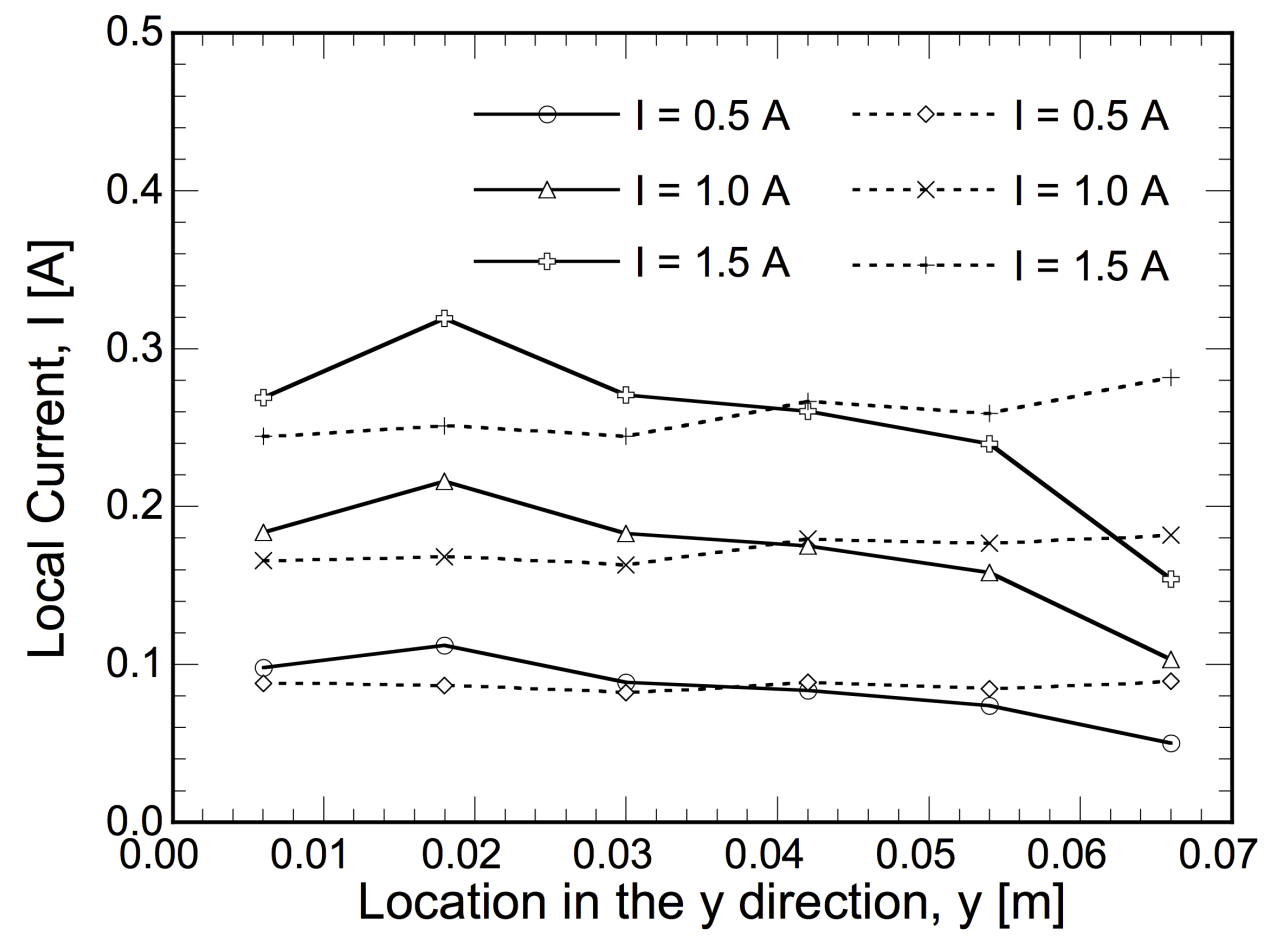

Figure 14: Zhang, Verma and Pitchumani 
(a)

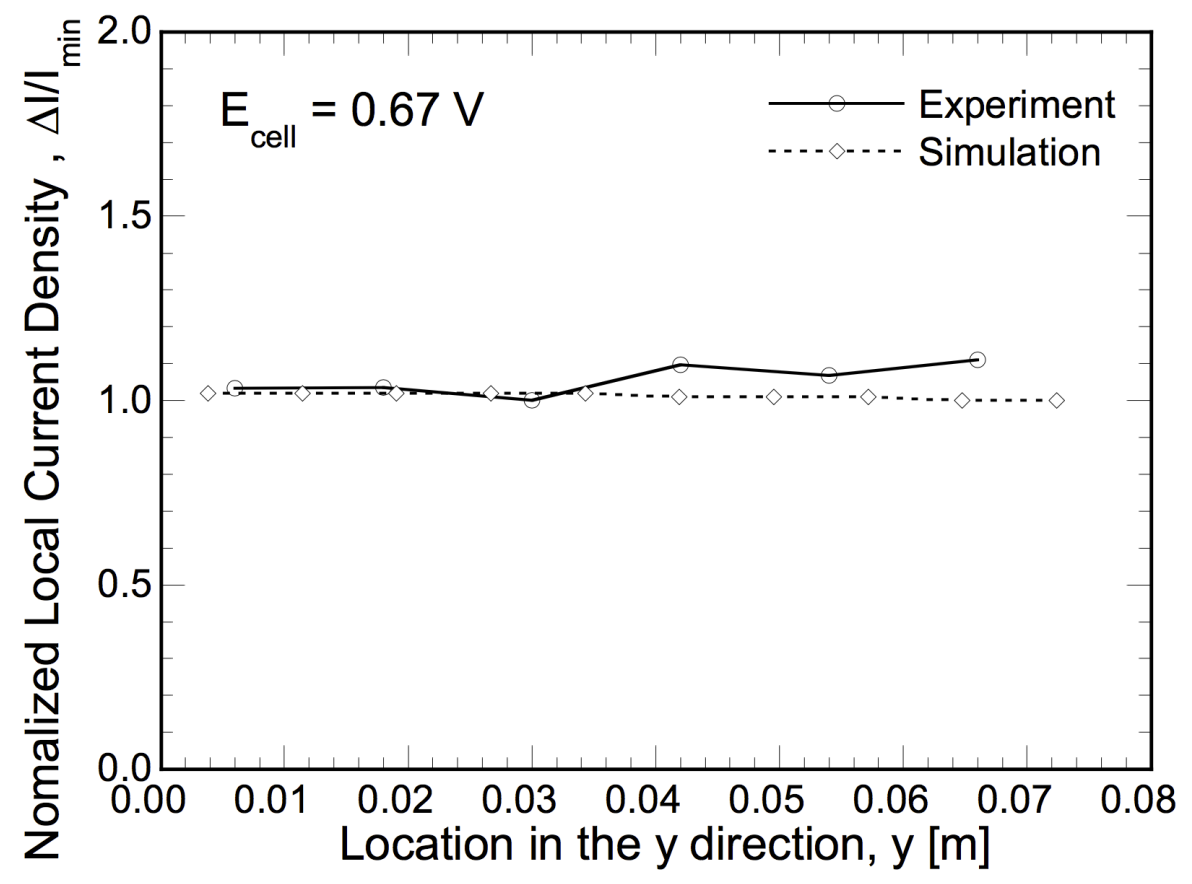

(b)

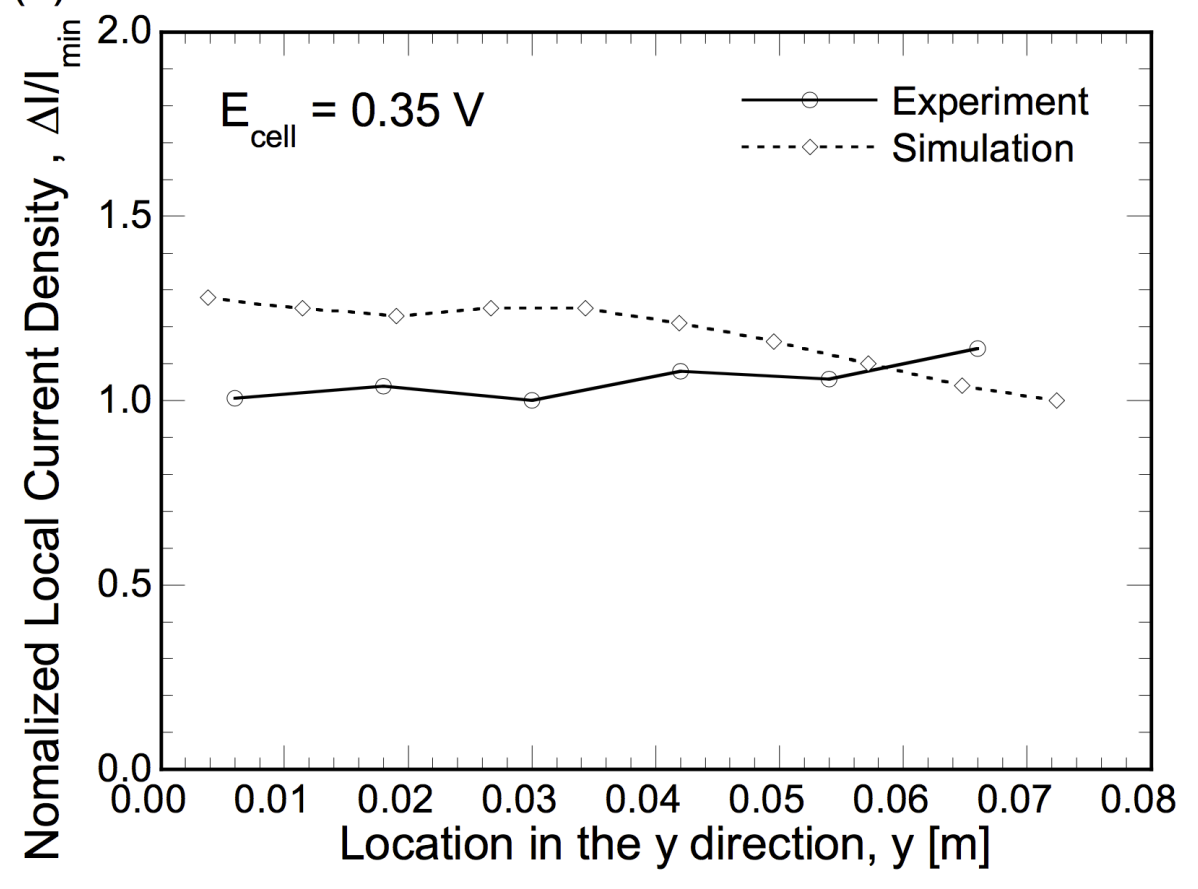

Figure 15: Zhang, Verma and Pitchumani 


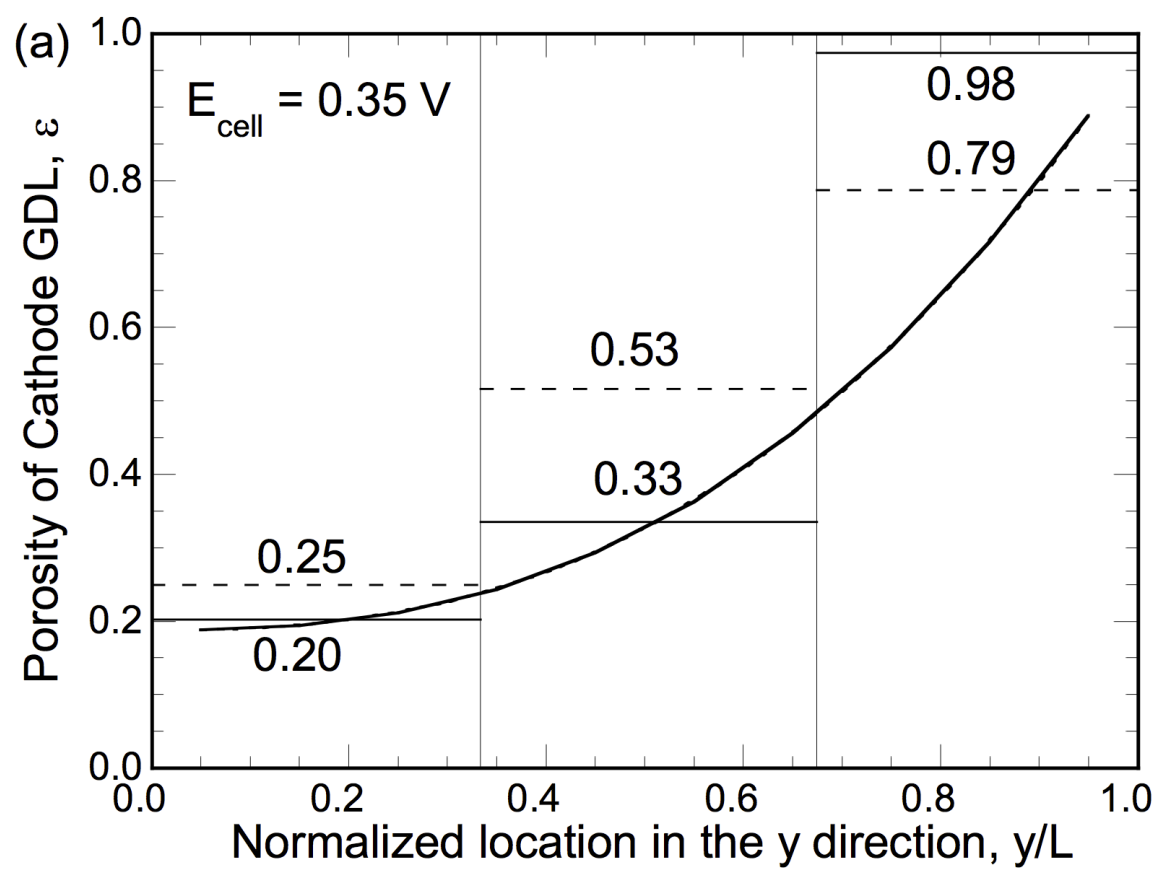

(b)

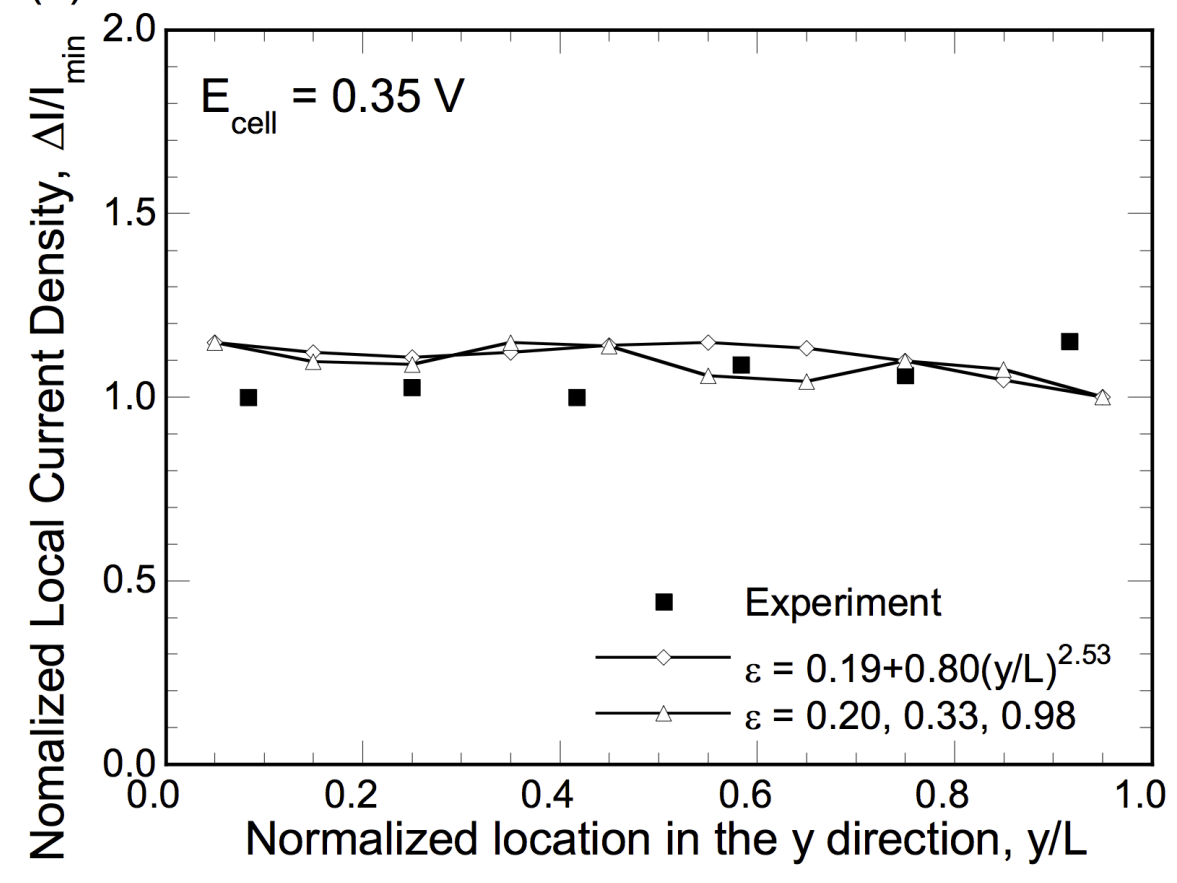

Figure 16: Zhang, Verma and Pitchumani 
Table 1: Source terms in the governing equations

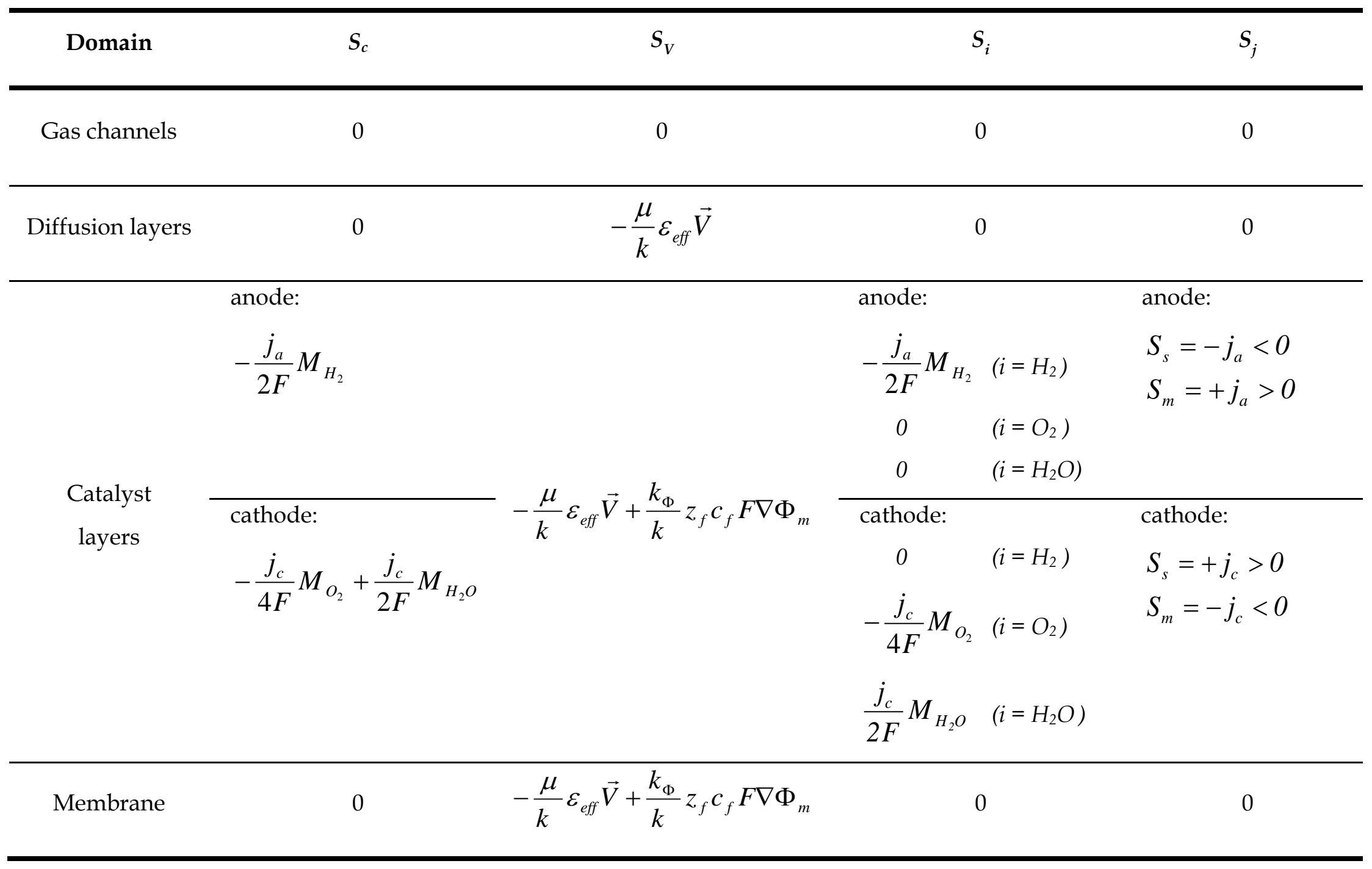


Table 2: Physical and geometry parameters used in the numerical simulations $[1,2,35]$

\begin{tabular}{|c|c|c|}
\hline Parameter & Symbol & Value \\
\hline Length of $\mathrm{H} 2$ chamber $(\mathrm{cm})$ & $L$ & $1.68 / 5.00$ \\
\hline Metal mesh (screen) width (mm) & & 0.5 \\
\hline Gas diffusion width (mm) & & 0.3 \\
\hline Catalyst layer width (mm) & & 0.016 \\
\hline Membrane width (mm) & & 0.018 \\
\hline $\mathrm{H}_{2}$ chamber width (mm) & & 3.2 \\
\hline Permeability of diffusion layer $\left(\mathrm{m}^{2}\right)$ & $k$ & $2.97 \times 10^{-9}$ \\
\hline Gas diffusion porosity & $\varepsilon$ & 0.776 \\
\hline Anode reference exchange current density $\left(\mathrm{A} / \mathrm{m}^{3}\right)$ & $j_{a, r e f}$ & $1.0 \times 10^{8}$ \\
\hline Cathode reference exchange current density $\left(\mathrm{A} / \mathrm{m}^{3}\right)$ & $j_{c, r e f}$ & 3000 \\
\hline Hydraulic permeability of membrane $\left(\mathrm{m}^{2}\right)$ & $K_{p}$ & $1.58 \times 10^{-18}$ \\
\hline Electrokinetic permeability $\left(\mathrm{m}^{2}\right)$ & $K_{\phi}$ & $1.13 \times 10^{-19}$ \\
\hline $\mathrm{H}_{2} \mathrm{O}$ viscosity in the membrane $(\mathrm{kg} /(\mathrm{m} \mathrm{s}))$ & $\mu_{\mathrm{H}_{2} \mathrm{O}}$ & $8.91 \times 10^{-4}$ \\
\hline Anode/cathode transfer coefficient & $\alpha_{a} / \alpha_{c}$ & $0.5 / 2.0$ \\
\hline Fixed site charge & $Z_{f}$ & -1 \\
\hline Membrane water porosity & $\varepsilon_{m}$ & 0.28 \\
\hline Volume fraction membrane in catalyst layer & $\varepsilon_{m c}$ & 0.5 \\
\hline Fixed charge concentration $\left(\mathrm{kmol} / \mathrm{m}^{3}\right)$ & $C_{f}$ & 1.2 \\
\hline $\mathrm{H}_{2}$ diffusivity in catalyst layer and membrane $\left(\mathrm{m}^{2} / \mathrm{s}\right)$ & $D_{H_{2}, \text { cata }}$ & $2.59 \times 10^{-10}$ \\
\hline $\mathrm{H}_{2}$ diffusivity in gas $\left(\mathrm{m}^{2} / \mathrm{s}\right)$ & $D_{H_{2}, r e f}$ & $1.1 \times 10^{-4}$ \\
\hline $\mathrm{O}_{2}$ diffusivity in gas $\left(\mathrm{m}^{2} / \mathrm{s}\right)$ & $D_{O, r e f}$ & $3.2 \times 10^{-5}$ \\
\hline $\mathrm{H}_{2} \mathrm{O}$ diffusivity in gas $\left(\mathrm{m}^{2} / \mathrm{s}\right)$ & $D_{\mathrm{H}_{2} \mathrm{O}, \text { ref }}$ & $7.35 \times 10^{-5}$ \\
\hline $\mathrm{O}_{2}$ diffusivity in catalyst layer and membrane $\left(\mathrm{m}^{2} / \mathrm{s}\right)$ & $D_{O_{2}, \text { cata }}$ & $8.328 \times 10^{-10}$ \\
\hline Thermal conductivity of screen mesh $(\mathrm{w} /(\mathrm{m} \mathrm{k}))$ & & 91.7 \\
\hline Thermal conductivity of carbon $(\mathrm{w} /(\mathrm{m} \mathrm{k}))$ & & 1.3 \\
\hline Thermal conductivity of catalyst layer ( $w /(m ~ k))$ & & 1.0 \\
\hline Thermal conductivity of membrane $(\mathrm{w} /(\mathrm{m} \mathrm{k}))$ & & 0.24 \\
\hline
\end{tabular}

